Portland State University

PDXScholar

Spring 6-4-2015

\title{
The Cognitive Development of Expertise in an ESL Teacher: A Case Study
}

Lyndsey Roos

Portland State University

Follow this and additional works at: https://pdxscholar.library.pdx.edu/open_access_etds

Part of the Higher Education and Teaching Commons

Let us know how access to this document benefits you.

\section{Recommended Citation}

Roos, Lyndsey, "The Cognitive Development of Expertise in an ESL Teacher: A Case Study" (2015).

Dissertations and Theses. Paper 2395.

https://doi.org/10.15760/etd.2392

This Thesis is brought to you for free and open access. It has been accepted for inclusion in Dissertations and Theses by an authorized administrator of PDXScholar. For more information, please contact pdxscholar@pdx.edu. 
The Cognitive Development of Expertise in an ESL Teacher: A Case Study

\author{
by \\ Lyndsey Roos
}

A thesis submitted in partial fulfillment of the requirements for the degree of

\author{
Master of Arts \\ in \\ Teaching English to Speakers of Other Languages
}

Thesis Committee:

Tetyana Sydorenko, Chair

Nike Arnold

Kathy Harris

Portland State University

2015 


\begin{abstract}
This case study investigated how an English as a Second Language (ESL) teacher's cognition has both changed and stayed constant over a period of eight years and the factors to which the teacher attributes changes or lack of changes. The study followed the teacher over the course of a 10-week period and compared videos of the participant's teaching from eight years ago to her current teaching. Interviews, observations, and stimulated recall were used to investigate development over the eight year span. It was found that the teacher did indicate several areas in which she demonstrated change: Teaching with fluidity, automaticity, and intuition; confidence; concerns; management of teaching enthusiasm and relationships with students; support and validation from colleagues; and managing the classroom for learning. She also confirmed several aspects of her teaching that have stayed relatively constant: beliefs and teaching philosophy; reflection; learning from past experiences; knowledge of lesson planning and curricular goals; and students' needs within the learning context. The teacher's development was analyzed through the lens of teacher expertise to determine to what degree the teacher's changes and lack of changes helped her develop into an expert. This study concludes that further research is needed to fully understand how teacher expertise is developed during the course of teachers' careers.
\end{abstract}




\section{ACKNOWLEDGMENTS}

I would first and foremost like to thank my advisor, Tetyana Sydorenko, for all of her help during the year I spent researching and writing this thesis. Her guidance and encouragement were invaluable to me. I am incredibly appreciative of her willingness to give me thoughtful and helpful feedback, even during her busy schedule. I am also indebted to my other two committee members, Nike Arnold and Kathy Harris. Thank you so much for helping me throughout this endeavor, from the early stages of planning my proposal to finally reading the final draft of my thesis. Finally, I would like to thank my participant, the talented educator who graciously accepted my offer to participate in this study. She exceeded all my expectations in her generosity of time and dedication to this project. Her thoughtful preparation and responses to all my questions were invaluable and I am tremendously grateful for all the rich data she provided.

I am also grateful to the all members of the department who have helped to shape me during my three years in this program. I have learned so much about Applied Linguistics because of your knowledge and insight. I feel prepared and excited to teach English because of the supportive intellectual environment I experienced in this department.

Finally, thank you to my family, boyfriend, and friends who supported and encouraged me throughout this process. Your love and encouragement meant the world to me during this experience. 


\section{TABLE OF CONTENTS}

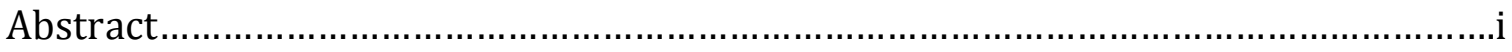

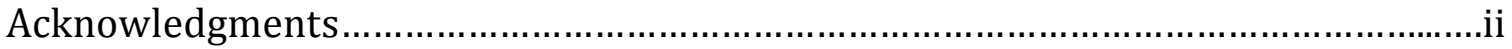

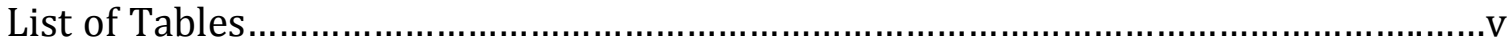

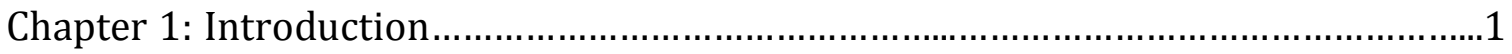

Chapter 2: Review of the Literature..................................................................

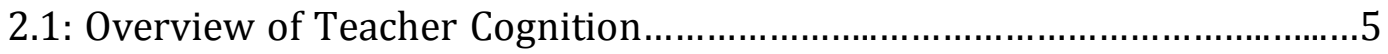

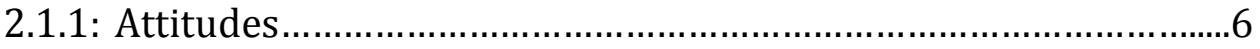

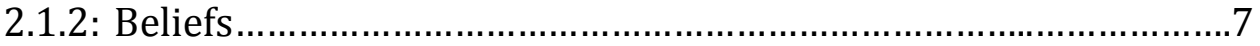

2.2: What Shapes Teacher Cognition?...................................................................9

2.2.1: Observations of Previous Teachers and Environments................9

2.2.2: Second Language Learning......................................................10

2.2.3: Teacher Education Courses....................................................10

2.2.4: Teacher Reflection.............................................................12

2.2.5: Teaching Context....................................................................13

2.3: Change Over Time from Novice to Experienced Teacher...........................13

2.3.1: Cognitive Development................................................................13

2.3.2: Teacher Concerns................................................................... 14

2.3.3: Classroom Practices.................................................................15

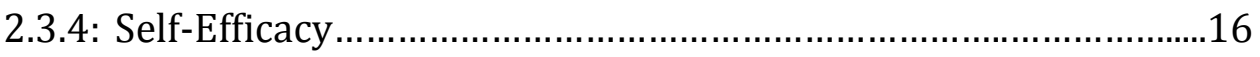



2.4.1: Overview of Expertise............................................................17

2.4.2: Expertise in Teaching.............................................................20

2.5: Limitations of Previous Studies and Further Research.............................22

2.5.1: Teacher Cognition.................................................................22

2.5.2: Teacher Expertise................................................................24

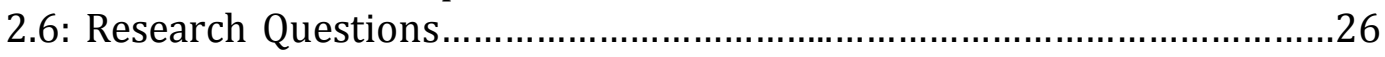

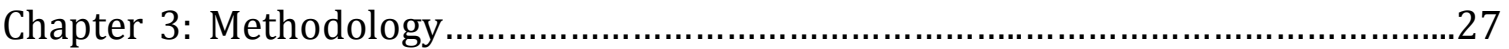

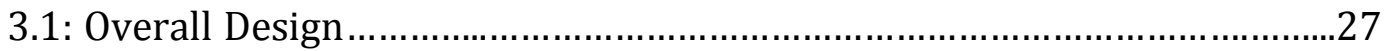

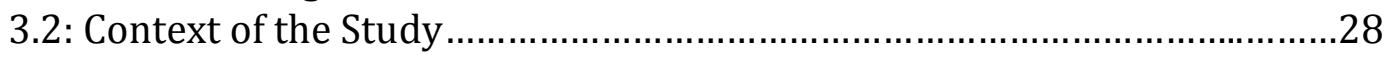

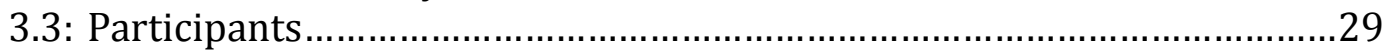

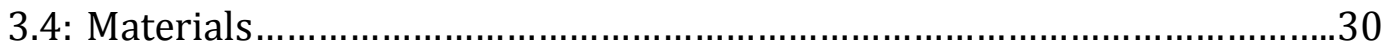

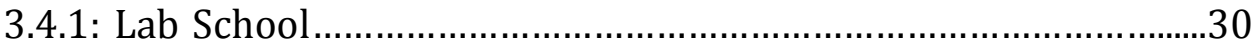

3.4.2: Multimedia Adult English Learner Corpus..................................31

3.5: Data Collection Procedures.......................................................................

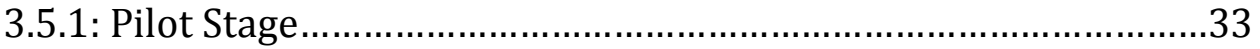

3.5.2: Video-Stimulated Recall...........................................................34

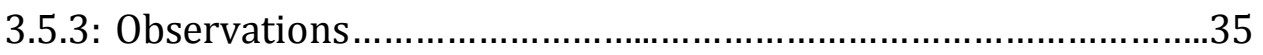

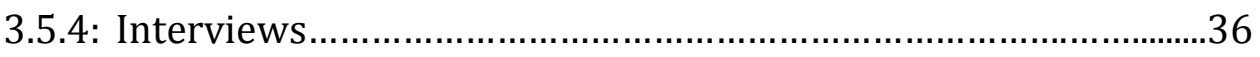


3.5.5: Previous Literature.....................................................................39

3.5.6: Timing of Data Collection.........................................................4

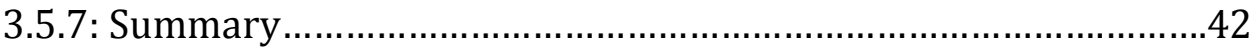

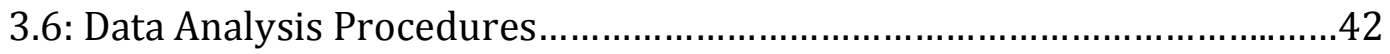

Chapter 4: Results and Discussion..................................................................

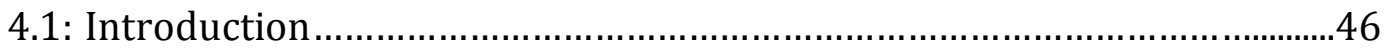

4.2: Rebecca's Educational Background........................................................47

4.3: Development Over Time: Changes, Modifications, and Adjustments.......49

4.3.1: Teaching with Fluidity, Automaticity, and Intuition..................49

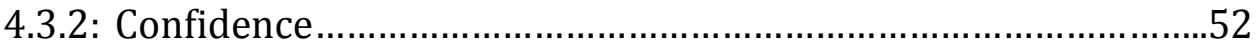

4.3.3: Concerns..............................................................................55

4.3.4: Management of Enthusiasm and Relationships with Students...57

4.3.5: Support and Validation from Colleagues..................................61

4.3.6: Managing the Classroom for Learning......................................62

4.4: Development Over Time: Staying the Course ..........................................65

4.4.1: Beliefs and Teaching Philosophy ...............................................66

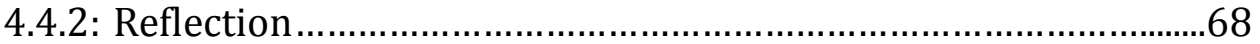

4.4.3: Learning from Past Experiences................................................70

4.4.4: Knowledge of Lesson Planning and Curricular Goals................72

4.4.5: Students' Needs within the Learning Context...........................74

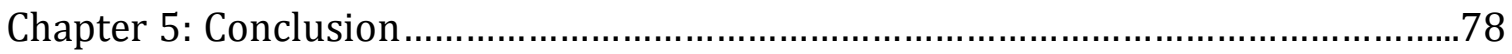

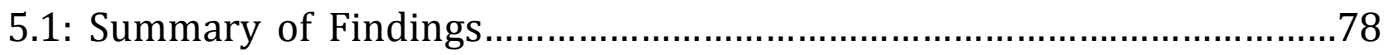

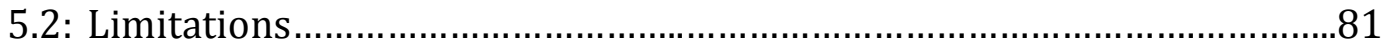

5.3: Implications and Suggestions for Future Research............................83



Appendix 


\section{LIST OF TABLES}

Table 1: Summary of Data Analysis and Recurring Themes...................................40

Table 2: Schedule of Data Collection ....................................................................... 41

Table 3: Summary of Analysis Codes based on Findings from Data Sources.............46 


\section{CHAPTER 1: INTRODUCTION}

The purpose of this study is to add to the body of research on teacher cognition by conducting a qualitative case study of an academic English as a Second Language (ESL) teacher's cognitive development as an experienced teacher. Much has been written about the persistence of teacher cognition upon entering and exiting pre-service teacher education programs. However, little research has explored teacher cognition over the career span (Alger, 2009). Alger (2009) found that, given time and experience, approximately two-thirds of teachers will change their conceptual views of teaching over the course of their careers. Therefore, researchers need to devote more time and attention to better understanding what teachers think and believe about whether their teaching has changed or remained unchanged and what might account for this development.

This study began by investigating changes and lack of changes in one teacher working in the Intensive English Language Program (IELP) at Portland State University (PSU) over a period of eight years, and what these changes or lack of changes mean for her teaching today. An iterative process was used such that data collection was informed by each stage of analysis. The original goal of this study was to assess whether this teacher did or did not indicate change through the later part of her career. The impact that these changes or consistencies have had on her teaching and how they have affected her cognitive development were of particular interest. During the data collection process, it became clear that this teacher was 
both experienced and highly competent, so whether or not she had developed into an expert teacher became an area of interest. I decided to investigate this teacher in reference to whether her characteristics of expertise were consistent with or diverged from the characteristics of expert teachers from prior literature.

Teacher expertise is an important area of teacher cognition that deserves more attention in the field of ESL. Many people think of expertise as only related to experience, or the number of years someone has been in a particular field, but expertise is a much more complex construct than experience. Teacher expertise is characterized as a highly proficient individual's quantity and quality of knowledge about teaching (Farrell, 2014). However, expertise has sparked varying debates among researchers about how it should be characterized. Some view expertise as a process involving continual hard work and dedication (Bereiter and Scardamalia, 1993; Tsui, 2003, 2005), while others view it as an intuitive and unconscious skill developed after years of diligent work (Dreyfus and Dreyfus, 1986). The dichotomy between the Dreyfus and Dreyfus (1986) model and the Bereiter and Scardamalia (1993) model were examined in the present study because further research into these two ideas is important to gaining a greater understanding of expertise as a whole. In the field of Applied Linguistics, expertise and the process of developing into an expert deserve more attention because further research into how teachers develop expertise can help us understand how to identify and cultivate this skill in less experienced teachers. This in turn would lead to larger numbers of expert teachers and more quality teaching in schools (Farrell, 2014; Tsui, 2005). 
The established goal of this study is to shed light on how an experienced ESL teacher has developed into an expert teacher and whether she has seen changes in her cognition and related practices that have facilitated her development. In order to accomplish this, I examined the teacher's views on how her cognition, or her beliefs, attitudes, and knowledge, have changed over time and whether this has influenced the way she approaches her current teaching. Using the significant amount of data available through Portland State University's ESOL Lab School in the form of video recordings of one of the teacher's classes, viewings of the recordings were conducted with the participant. Observations and interviews were also conducted during the present study to discuss her knowledge, beliefs and attitudes about teaching, and specific examples of how her teaching has developed based on the similarities and differences between her teaching now and at the time of the videos. The purpose of this data collection process was to allow the teacher to reflect on the classes she taught in the past and compare herself with the teacher that she is today. This allowed her to assess whether she believed certain aspects of her teaching had changed and possible reasons for this development. By analyzing the data and comparing her teaching to the categories used to define expert teachers in prior research, this study suggests that this teacher has in fact developed into an expert.

This thesis consists of five chapters. In what follows, in the second chapter, I discuss previous literature on teacher cognition and expertise, and state gaps in the prior research and areas in need of further study. I explain how my research will 
contribute to the field and state my research questions. In Chapter 3, I describe how I conducted my study and the methods used for data collection and analysis. In the fourth chapter, I present my results and discussion. Finally, in the fifth chapter, I conclude with a summary of my findings, describe the limitations of my study, and discuss areas for further research. 


\section{CHAPTER 2: REVIEW OF THE LITERATURE}

\section{OVERVIEW OF TEACHER COGNITION}

Teacher cognition is defined as "the unobservable cognitive dimensions of teaching - what teachers know, believe, and think," and how they came to have these beliefs and knowledge about teaching (Borg, 2003, p. 81). The field of teacher cognition seeks to answer complex questions about how teachers come to know what they know about teaching and how this knowledge translates into their practices in the classroom. Woods (1996) further defined teacher cognition as consisting of the integration of beliefs, assumptions, and knowledge (BAK). There is a growing consensus that in order to understand language teaching better, we need to better understand what teachers know, how they come to know it, and how they draw on their knowledge (Ellis, 2006).

Freeman, a prominent researcher in this field, conceptualized the important factors in teacher cognition: teaching is seen as the result of skills, knowledge, attitudes, and awareness (Freeman, 1989). Within this model, skills, or the how of teaching, are composed of methods, activities, techniques, and materials. Knowledge, or the what of teaching, is made up of subject matter, knowledge of students, and sociocultural and institutional knowledge. These two factors are influenced by teachers' awareness and attitude, or their stance toward themselves, their activity and others that links intrapersonal dynamics with external performance and behaviors. Integral to the model is the idea that teaching is not 
static because it involves constant shifts, negotiations, and responses to numerous variables (Freeman, 1989).

Borg (2003) also summarized teacher cognition as emerging from the interplay between four main factors: schooling, professional coursework, contextual factors, and classroom practice. Schooling, or the experience of being in a classroom, defines early cognitions and shapes teachers' perceptions of initial training. Professional coursework, or the information teachers are exposed to during teacher education and training, also impact existing cognitions. Contextual factors influence practice by modifying cognitions or lead to change by exposing possible disconnects between knowledge and practice. Classroom experience, including practice teaching, can influence cognition unconsciously or through conscious reflection. These factors all come together to create the networks of beliefs, knowledge, and thoughts which language teachers hold about all aspects of their profession and which they draw upon in their practice. This model reflects the prevalent view in the field that many factors play a role in shaping teacher cognition and this integrated knowledge relates closely to the work of teachers in the classroom (Borg, 2003).

\section{Teacher Attitudes}

As mentioned above, attitudes are an important aspect of teachers' cognitive systems. Tsui (2003) argues that expert teachers are characterized not just by what they can do, but rather "how they understand and perceive what they do" (p. 246). Thus, teachers' attitudes toward their teaching can determine how effective they are 
in the classroom. Although few studies have focused on teacher attitudes alone, Bell (2005) outlined several attitudes that the teachers in her study agreed were positive attitudes for effective foreign language teaching. These positive attitudes include: genuine caring and kindness, a willingness to share classroom responsibilities, a sincere sensitivity to the students' diversity, a motivation to provide meaningful learning experiences for all students, and an enthusiasm for stimulating the students' creativity. The study demonstrated an emerging professional consensus that these attitudes help teachers be effective in the classroom.

If new or developing teachers are aware of these attitudes that experienced foreign language teachers believe to be effective in teaching, they will be able to critically reflect on their own beliefs and teaching behaviors and they may be able to integrate these attitudes into their own cognition (Bell, 2005). This can help to improve their teaching because effective attitudes and actions employed by teachers have the ability to make a positive difference in the lives of their students (Bell, 2005). Therefore, understanding teachers' attitudes toward teaching and why they have the attitudes that they do is important for understanding how effective they are.

\section{Teacher Beliefs}

Beliefs are an important aspect of teacher cognition and it is widely believed that teachers' beliefs play a significant role in their teaching practices (Borg, 2003). Many studies have investigated the role of teacher beliefs in a variety of different 
contexts (Burns, 1992; Mok, 1994; Nespor, 1987; Woods, 1996; Zheng, 2013), including comparing inexperienced and experienced teachers' stated beliefs and their relationship to their classroom practices (Basturkmen, Loewen, \& Ellis, 2004; Fang, 1996; Sendan \& Roberts, 1999) and change in beliefs or resistance to change over time (Borg, 2011). It has been suggested that language teachers' principles become embedded 'with experience' (Breen, Hird, Milton, Oliver, \& Thwaite, 2001, pp. 472-473), and that principles or beliefs informed by teaching experiences are expected to correspond more clearly with teaching practices (Basturkmen, 2012). Therefore, it might be expected that deeply held principles would be applied more consistently than principles acquired more recently as we might expect in the case of new teachers (Breen et al., 2001).

However, Farrell and Bennis (2013) explored practices that converged with or diverged from stated beliefs in a novice and an experienced teacher. They conclude that teachers possess a set of complex beliefs that are not always realized in their classroom practices. In their study, a more experienced teacher had more experientially informed beliefs than a novice teacher, and these beliefs were more in line with the experienced teacher's classroom practices. However, the researchers found that these beliefs sometimes diverged from his classroom practices for a variety of reasons, including time constraints, desire to maintain rapport with students, and other 'realities of the classroom' (p. 175). The authors state that both an experienced teacher and a novice teacher "showed instances of convergence and 
divergence that were not always easy to distinguish" (Farrell \& Bennis, 2013, p. 175).

WHAT SHAPES TEACHER COGNITION?

\section{Observations of Previous Teachers and Environments}

As mentioned above, there are many interconnected factors that shape language teacher cognition. The experience of simply being a student exposed to different styles of teaching affects how education students form their initial views about teaching. Lortie (1975) described teachers' apprenticeship of observation, or the subconsciously developed conceptions of teaching cultivated by their experiences as learners in both general and language education classrooms. Teachers' initial beliefs about teaching develop from what they experience as participants in the public side of education. They are necessarily unable to experience the private side of education, or the thought processes in the minds of their teachers. Pre-service teachers, then, are not aware of the conceptualizations that serve as the foundations for why teachers do what they do. It is only when they begin their journey into education that this develops (Freeman \& Richards, 1993). These experiences as students can create deeply held beliefs about teaching that are carried with pre-service teachers as they enter professional development programs. Therefore, teachers' learning experiences as students solidify a set of beliefs about teaching that can have a tremendous impact on classroom practices, views about the role of the teacher and learner, and learning to teach in general (Alger, 2009). 
Second Language Learning

In addition to classroom experiences during primary and secondary school, the important role of second language learning has been examined by several researchers (Basturkmen, 2012; Ellis, 2006; Flowerdew, 1998) who argue that language teacher cognition is greatly influenced by teachers' experiences learning a second language. According to Basturkmen (2012), teachers' preliminary ideas about second language teaching are largely based on their own experiences as language learners. Language learning experiences during formative years can lead to key insights which teachers draw from in framing their approach to their own learners. Flowerdew (1998) found that experiencing the difficulties that second language learners encounter gave teachers insights into how to teach a second language "in a way that helps the students most, based on the general teaching principles" they generated while learning a second language (Flowerdew, 1998, p. 529). Ellis (2006) further argues that "insights gained from personal experience, particularly language learning experience, are of a different nature from the knowledge and beliefs gained in formal teacher education," but they interact with them cohesively to form a comprehensive cognitive understanding of teaching (A Framework for Examining Teachers' Knowledge and Beliefs section, para. 6). Therefore, experiences learning a second language help to formulate language teachers' professional knowledge and belief systems.

Teacher Education Courses 
Content knowledge and growth during teacher education is another area of interest in teacher cognition (Freeman \& Richards, 1993; Macalister, 2012; Sanchez, 2013; Verloop, 2001), and consequently the question of what it is that teachers need to know in order to reach their full potential as language educators. Content knowledge refers to the subject matter of language teaching, or what teachers need to know about what they teach (Richards, 2010) and constitutes knowledge that would not be shared with teachers of other subject areas. Understanding of language is a key factor because both native and non-native speaking teachers must have enough understanding of the target language to be confident, prepared instructors. Of particular relevance is pedagogical knowledge which is "drawn from the study of language teaching and language learning itself and which can be applied in different ways to the resolution of practical issues in language teaching" (Richards, 2010, p. 105). A sound grounding in relevant pedagogical knowledge should prepare teachers to perform the tasks that are necessary for teaching a class of foreign/second (L2) language learners.

Despite the importance of knowledge gained through teacher education courses, many new teachers find that content and pedagogical knowledge alone is insufficient to prepare them to be confident, informed, and effective teachers in the classroom. This is reflected in Richard's (1996) conceptualization of teaching maxims. Teachers' maxims are the "outcomes of teachers' evolving theories of teaching. They are personal working principles which reflect teachers' individual philosophies of teaching, developed from their experience of teaching and learning, 
their teacher education experiences, and from their own personal beliefs and value systems" (Richards, 1996, p. 293). Teaching maxims are developed through teacher education as well as practical pre-service teaching experiences. According to Carter and Doyle (1995), teachers' development occurs as a result of the interplay between personal beliefs, based on teachers' backgrounds, the knowledge they gain from teacher education courses, and their practical teaching experiences. Thus, the factors inherent in teaching maxims play a crucial role alongside pedagogical and content knowledge.

\section{Teacher Reflection}

Teacher reflection is widely believed to have direct effects on teacher cognition and is a crucial factor in teachers' development over time (Kang \& Cheng, 2014; Richards, 2010). This explains its prevalence in many teacher education programs. According to Freeman and Richards (1993), teacher knowledge exists in very personal terms so it is important to recognize the impact that teachers' experiences have on the formation of their professional knowledge and beliefs, while still acknowledging their ability to develop and change over time. "A powerful tool to bring about change in teachers is to enable teachers to reflect on their own teaching so that they can make explicit their implicit beliefs" (Ping, 2010, p. 443). Reflection can help teachers reconcile their experiences as students in order to determine the best pedagogical choices for their classrooms and facilitate their improvement (Mann, 2005). 


\section{Teaching Context}

Teachers' contexts of work also affect their cognitions. Tsui (2003) writes that "the development of teacher knowledge is jointly constituted by the teachers' specific context of work and their interaction with the context" (p. 280). Furthermore, Johnson (2006) acknowledges that second language teacher knowledge, linguistic and otherwise, is understood as "normative and lifelong, as emerging out of and through experiences in social contexts: as learners in classrooms and schools, as participants in professional teacher education programs, and later as teachers in the settings where they work" (as cited in Reeves, 2009, p. 109). Therefore, how well a teacher relates to and understands their context is clearly an important aspect of their ability to function competently as a teacher within that context.

\section{CHANGE OVER TIME FROM NOVICE TO EXPERIENCED TEACHER}

\section{Cognitive Development}

Cognition not only shapes what teachers do in the classroom, but is in turn shaped by teachers' accumulated experiences (Borg, 2003). Several studies (Burns, 1992; Mok, 1994; Richards, Li \& Tang, 1998; Tsui, 2003; Woods, 1996; Zheng, 2013) have focused on comparing inexperienced and experienced teachers' cognitive development. Studies comparing experienced teachers with their less experienced peers have shed light on changes in teaching that can occur over time (Borg, 2003). 
Nunan (1992) conducted a study showing that experienced language teachers' decisions showed greater attention to language issues than those of less experienced teachers, who were more likely to be concerned with classroom management, and devote more time and focus to maintaining it. This suggests that more experienced teachers are able to focus more attention on issues of content as they learn strategies to automatize the routines associated with managing the class. Additionally, Richards, Li and Tang (1998) compared novice and experienced teachers and identified areas of pedagogical knowledge in which novice teachers were less skilled. These studies suggest that the cognition of beginning teachers is likely to change in various ways as they gain experience.

\section{Teacher Concerns}

Teacher concerns are cognitive influences that can greatly affect language teachers' classroom practices (Borg, 2003). Early research by Fuller (1969) outlined a model which conceptualized the development of teachers as passing through phases which are sequential and accumulative. During early pre-service preparation, prospective teachers are characterized as not concerned about teaching, but concerned instead with their own progress as students. Early field experience in teacher preparation leads prospective teachers to become concerned about their survival as teachers (self concerns). As they continue in teacher preparation, their concerns focus upon their actual performance as teachers (task concerns). Finally, after experiencing successful teaching experiences, more mature 
teachers' concerns focus on having a meaningful and positive impact on their students (impact concerns).

Pigge and Marso (1997) conducted a longitudinal study over a period of seven years. They tracked a group of teachers starting with two years of teacher education and continuing through the first five years of teaching, while analyzing the development of the teachers through the stages of Fuller's model. They found that teachers' concerns did change throughout the span of seven years, but that there were not always strong correlations between experience and moving directly through the stages as predicted by Fuller. Teachers did not move routinely from one phase to another and sometimes moved in and out of phases. This study of concerns presents a unique way of looking at cognitive development over time because we can think of teaching concerns as being cyclical and unique to individuals in various contexts.

\section{Classroom Practices}

Many studies (Alger, 2009; Pickering, 2005; Sendan \& Roberts, 1999; Woods \& Cakir, 2011) have looked at change by comparing beginning teachers with more experienced teachers who have one or more years of experience in the field. While many studies have compared experienced and inexperienced teachers (Borg, 2003), only a few studies have focused on tracking one or a few teachers' changes over time. Kang and Cheng (2014) conducted a case study of one novice EFL middle school teacher and observed that she exhibited a considerable amount of change in 
her classroom practices. This was attributed to a number of interconnected factors, including teacher experience, reflection on practice, and the teaching context. The study concluded that the development of this teacher's cognition was the result of the cyclical interaction between the teacher's knowledge and belief system and her classroom practices. The cyclical nature of change was demonstrated by Huberman (1995), who argued that "changes in beliefs lead to changes in practice that bring changes in student learning that bring further changes in practice that result in additional changes in belief and so on" (as cited in Wong, 2013).

\section{Self-Efficacy}

Teachers' self-efficacy is their judgments about their ability to promote student learning (Hoy and Spero, 2005). This judgment is concerned with perceptions of competence rather than actual levels of competence, which reflects the degree of confidence teachers have in their abilities (Hoy \& Spero, 2005). Hoy and Spero (2005) suggest that growth of self-efficacy during "the first years of teaching could be critical to the long-term development of teacher efficacy" (p. 344). They studied beginning teachers to determine if there were changes in the teachers' self-efficacy from entry into a teacher preparation program through the first year, and concluded that their efficacy increased during student teaching, but declined during the first year of teaching. Thus, self-efficacy and the subsequent confidence teachers feel have been shown to be a possible source of change during the course of teachers' years in the field. 
Additional previous studies have shown that self-efficacy beliefs cause teachers to be more open to new ideas, less critical of students who make mistakes, and influence "teachers' persistence when things do not go smoothly and their resilience in the face of setbacks" (Hoy and Spero, 2005, p. 345). Furthermore, Yazdi, Motallebzadeh, and Ashraf (2014) found that teachers' self-efficacy, where selfefficacy is defined as an individual's confidence in their ability to engage in social interaction to initiate and maintain interpersonal relationships, has a reverse relationship with teacher burnout. Burnout is defined as the resulting fatigue, frustration, and dissatisfaction of long-term, job-related stress (Yazdi et al., 2014, p. 1198). Hoy and Spero (2005) also describe a possible link between burnout in teaching and "professional efficacy discrepancy, or the distance between expected and actual levels of professional performance" (p. 346). This points to the idea that self-efficacy can affect many different areas of a teacher's development.

\section{EXPERTISE}

Overview of Expertise

Within teacher cognition, the area of teacher expertise focuses on the factors that allow a teacher to be characterized as an expert, or someone highly proficient within a specific field. Expertise across a variety of disciplines is thought to be characterized by an individual's quantity and quality of knowledge about a particular topic (Farrell, 2014). Thus, an expert must not only have a large amount of knowledge, but also an ability to interact with that knowledge in a judicious and 
insightful way. Experience, or the amount of time spent developing a skill, has also been thought to contribute to expertise (Farrell, 2014). However, although expertise has been equated with years of experience, the whole idea of experience necessarily leading to expertise has been questioned by various researchers (Farrell, 2014; Tsui, 2003). Thus, the complex concept of expertise is not only about a knowledge base or a number of years in a particular field, but encompasses how an individual relates to their knowledge and experience.

Another dimension of expertise is "the seemingly effortless performance on the part of experts because of their knowledge and skill" (Farrell, 2014). It is thought that experts, with their vast expanse of knowledge, do not need to think about a task as much because it has become 'second-nature'. Those lacking this knowledge and skill base often struggle or must put forth more exertion with the same task. However, the apparent ease of some experts should not diminish the fact that their work often includes immense effort; it just may appear easy and natural to those unfamiliar with their area of expertise (Farrell, 2014).

Farrell (2014)'s characterization of expertise draws from the model of skill acquisition proposed by Dreyfus and Dreyfus (1986) in which experts "make judgments based on their prior concrete experiences in a manner that defies explanation" (p. 36). Expertise is conceptualized as 'knowing how' rather than 'knowing that', which means that is it based on an expert's instinctive judgments and actions rather than a body of knowledge separate from the action (Dreyfus and 
Dreyfus, 1986). This draws from the work of philosopher Gilbert Ryle who, in The Concept of Mind (1949), suggests that professionals' knowledge is encompassed in the action, a kind of "knowing-in-action" that cannot be articulated (Tsui, 2003). To use a well-known example, riding a bike, most people know that pushing on the pedals moves a bike forward and that holding the handlebars and turning them steers the bike, but whether they know how to ride a bike is a different question. Having the ability to ride a bike involves a kind of practical knowledge gained from the experience of learning to ride a bike. Dreyfus argues that 'knowing how' is more important for expertise than 'knowing that' for the same reason why someone can know the mechanics of how a bike works but cannot ride one. An expert is someone who has mastered the 'knowing how' of their discipline, not just the detached, theoretical knowledge, and therefore, no longer has a need for conscious decisionmaking or problem solving. This model further proposes that because expertise is automatic, it is also non-reflective, and that the tacit 'knowing how' of experts makes it difficult for them to articulate why they can perform the way they do (Dreyfus and Dreyfus, 1986).

In contrast to the Dreyfus and Dreyfus (1986) model, Bereiter and Scardamalia (1993) take a different approach. They conceptualize experts as individuals who continue to work hard to improve their skills, even after many years in the field. After their experience has helped them develop routines for certain problems they may encounter in their specific domain, they are free to pursue new goals and solve problems at a higher level (Bereiter and Scardamalia, 
1993). Thus, by "reinvesting" their energy in more advanced problems, they are able to continue improving themselves. They define this process of seeking higher-level problems and working to find the best solutions as "progressive problem solving." For this reason, Bereiter and Scardamalia (1993) argue that rather than treating expertise as a state to be acquired, it should instead be conceptualized as a process. Even if one achieves a "state" of expertise, it is not certain whether that individual will be able to maintain a level of expertise without sufficient effort. Most research in expertise has compared experts with non-experts, but this is not likely to help us understand the process approach to expertise, or how it is acquired (Bereiter and Scardamalia, 1993). A greater understanding of the process of developing into an expert, the fluid nature of expertise, and whether this model stands up against the Dreyfus and Dreyfus (1986) model is important to gaining a greater understanding of expertise as a whole.

\section{Expertise in Teaching}

Tsui, a leader in the field of teacher expertise, outlines several characteristics of expert teachers that she has found during the course of her studies of experienced and inexperienced teachers. Expert teachers are able to exercise autonomy in decision making and respond flexibly to contextual discrepancies such as student responses and disruptions. In addition, expert teachers' are more efficient in lesson planning, and their lesson plans are usually brief. They are able to establish coherence between lessons and relate their lessons to the entire curriculum. Their 
thoughts during planning show a much more integrated knowledge base than novice teachers, and they are able to use that knowledge to deal with the complexities of the classroom (Tsui, 2003, 2005). According to a study by Farrell (2013), reflection is also a key component of understanding teacher expertise because it can act as tool for teachers to bring this usually unarticulated concept to a greater level of awareness. Richards, Li, and Tang (1998)'s study comparing inexperienced and experienced teachers investigated teachers' pedagogical content knowledge and how teachers solve problems that arise in the classroom. It was found that experienced teachers differed from inexperienced teachers in four main ways: thinking about the subject matter from the learners' perspective, acquiring a deeper understanding of the subject matter; presenting information in appropriate ways; and integrating language learning with overall curricular goals. Richards, $\mathrm{Li}$, and Tang (1998) highlight the importance of "examining how teachers conceptualize lessons and the contribution of subject matter expertise and experience to teachers' pedagogical reasoning skills" (p. 100).

Tsui $(2003,2005)$ critiques the conception of expertise put forth by Dreyfus and Dreyfus (1986) and claims that expert teaching is deliberate and involves a great deal of reflection. According to Tsui (2005), in language teaching, as in other domains, expert teachers are those who, when the task requires it, continually put more effort into their performance. She argues that expert teachers deliberately attempt to improve their techniques and knowledge, and this is what makes them experts (Tsui, 2005, pp. 179-182). These findings raise the issues of inspiration and 
enthusiasm as possible determining factors in the acquisition of expertise. In other words, the degree to which a teacher feels motivated to work to improve aspects of his or her teaching may affect their development into an expert teacher. This debate within teacher expertise, between the idea of an expert as working to improve their skills or performing tacitly with smoothness and ease, will be examined further in this study.

\section{LIMITATIONS OF PREVIOUS STUDIES AND FUTURE RESEARCH}

\section{Teacher Cognition}

Previous studies (Alger, 2009; Borg, 2003; Farrell, 2014; Tsui, 2003, 2005; Wong, 2013) demonstrate that further research into the development of teacher knowledge and beliefs over time could add valuable insights to the field of Applied Linguistics. In his review of the literature on teacher cognition, Borg (2003) states that researchers can only infer some of the possible changes language teachers experience in developing the cognitions and skills characteristic of more experienced teachers, because none of the studies he reported on were longitudinal. He elaborates,

Further research into the processes through which teachers' cognitions and practices are transformed as they accumulate experience is also required. Much existing insight into this issue is based on comparisons of experienced 
and novice teachers; longitudinal inquiries of how teachers actually change would be an important addition to existing research here. (Borg, 2003, p. 98)

The present study will be able to expand on these limitations by discussing an experienced teacher's change over a period of eight years. Previous studies have also highlighted the benefit of the qualitative case study approach to research in teacher change because this methodology allows one teacher's development to be examined in-depth. This approach will be used in the present study because of the importance of paying close attention to what actually happens in the classroom and working to understand teachers' inner motivations for their pedagogical actions.

Also within teacher cognition, there has been substantial research about the persistence of teacher beliefs upon entering and exiting pre-service teacher education programs, but little research has explored teacher beliefs over the career span (Alger, 2009). According to Alger (2009), given time and experience, approximately two-thirds of teachers will change their conceptual views of teaching over the course of their careers. Therefore, researchers need to devote more time and attention to better understanding what teachers think and believe about their own work in the classroom and how their cognition changes or remains unchanged. Understanding change during the course of teachers' careers is an important area for further investigation because empirical studies of teacher beliefs to date have yielded inconsistent findings (Wong, 2013). 
Borg (2003) asserts that there is a need for further research into how language teachers' thoughts and knowledge relate to learning and how cognitions and practices are transformed as they accumulate experience. It is important for researchers in Applied Linguistics to focus on how a teacher's cognitive system of beliefs, attitudes, and knowledge translate into creating better opportunities for student learning. Research has shown that as teachers develop into more experienced, better qualified teachers, they become more effectively able to respond to their students' needs (Borg, 2003). A qualitative study looking into teacher cognition and changes over a significant period of time would add much to the field of Applied Linguistics. This area deserves further attention and research because answers to these questions have direct correlations with policy decisions about teacher training and education. Therefore, more diverse research, on different aspects of teacher cognition, is necessary to strengthen the current findings in the field so as to enact positive changes in future policy decisions. For these reasons, this study investigated an experienced teacher's views and reflections on her changes or lack of changes over a period of time, including what factors may have contributed to changes or consistencies in her teaching.

\section{Teacher Expertise}

Early studies on teacher expertise mostly took the form of novice-expert comparisons by evaluating novice and expert teachers and how they differ in their classroom practices, thoughts, and beliefs (Farrell, 2013; Tsui, 2003). There is a 
need for more studies of expertise that investigate experienced teachers in-depth, rather than just comparing them to novice teachers. Tsui (2005) claims that expertise has received insufficient focus in the field of second language acquisition. "Relatively little work has been done on expertise in ESL teaching and still less on the development of expertise in ESL teaching" (Tsui, 2003, p. 3). Farrell (2014) also notes that research conducted on expertise in English language teaching has been limited and that further studies on the process of achieving expertise through reflection would be valuable. Thus, there is a need for more studies examining ESL teacher expertise and looking specifically at how it develops over time. Because there have already been several studies comparing experienced and novice teachers (Leinardt \& Greeno, 1986; Tsui, 2003), this study seeks to present an in-depth case study of the development of expertise of one experienced teacher over time, rather than comparing her to other teachers of various levels of experience.

Tsui (2005) notes that, “while there are numerous studies on teachers' professional growth over time, not many have been done from the perspective of expertise as a process" (p. 179) According to Bereiter and Scardamalia (1993), expertise has been treated as both a static and dynamic element. As a state, it can be conceived of as a state of competency within a given domain. However, within language teaching, this does not adequately account for the process of becoming an expert and maintaining expertise. The process through which a teacher achieves a level of expertise is of crucial importance to our understanding of this concept. While there have already been various studies comparing novice and experienced 
teachers and how they differ, further research is needed on how expertise is acquired and maintained. By only comparing experts and non-experts, it is difficult to fully understand expertise because expert teaching can be confused with experienced teaching (Bereiter \& Scardamalia, 1993). Therefore, studies of expertise should focus on the development of expertise, or the changes that occur in experienced teachers. Further research is needed to better understand expert teaching as a process and how an experienced teacher develops into an expert.

\section{RESEARCH QUESTIONS}

The focus of the present study changed during the course of data collection. I originally planned to focus on changes or lack of changes in teacher cognition and pick a more specific area within this field based on my findings. As evidenced by the data I collected, however, the study will address the following research questions:

1) What changes does an experienced academic ESL teacher report in her teaching over a period of eight years and how have they impacted her teaching?

2) How does expertise evidence itself in this teacher's changes or lack or changes in cognition (knowledge, beliefs, and attitudes)? 


\section{CHAPTER 3: METHODOLOGY}

\section{OVERALL DESIGN}

The planned study draws on the qualitative case study approach. Mackey and Gass (2005) characterize case study research as research that aims to provide a holistic description within a specific population and setting. Although case studies are limited in the difficulty of making generalizations from the specific case to the general population (Mackey \& Gass, 2005), the phenomenon in question can be studied in detail, providing rich contextualization to highlight the complexities involved. Another positive aspect of qualitative case studies is that they have the potential to provide in-depth analyses using rich and thick description. This study can be characterized as a case study because data from only one teacher was used and the complexities of her teaching experience were examined and analyzed.

Case study research has been shown to have great potential for examining development and change over time (Ping, 2010; Sun, 2012; Xu, 2013). Crookes and Arakaki (1999) showed that a teacher's set of beliefs is uniquely individual and best accessed by a case study approach focusing on one teacher rather than trying to understand the belief systems of many teachers at once. Personally individual aspects of teacher development, such as identity formation or change in identity over time, are ideal for case study research (Crookes \& Araki, 1999). For this reason, examining the very personal issues of teacher cognition and development over time is best done through a case study approach. Mackey and Gass (2005) suggest that 
findings from multiple case studies can be examined together to help researchers draw stronger conclusions. Thus, the present case study can add to existing research on teacher cognition. There is potential for more comprehensive conclusions to be drawn about change in teacher cognition by examining work done in other case studies.

According to Basturkmen (2012), case studies have essentially heuristic objectives designed to generate hypotheses. She argues that it is time to move research beyond description, and instead focus on more comparative case studies. She suggests comparing relatively experienced teachers with inexperienced teachers as an example (Basturkmen, 2012). The present study aimed to fill this gap in research by comparing a teacher at different points during her teaching career with the goal of examining differences and similarities between her cognition as a less experienced teacher and a more experienced teacher.

This case study followed a qualitative, exploratory design. The study is exploratory because I aimed to find information to answer the research questions, but I did not start with any particular hypothesis. Also pilot observations were conducted to serve as baseline data and inform the questions used in interviews. It is also highly qualitative because I focus on the social world of the participant, or her experience in a natural setting, and data was gathered through a variety of qualitative methods. 
The Intensive English Language Program (IELP) is a full immersion English program at Portland State University (PSU). It has offered academic English language instruction to thousands of international students since its establishment in 1964. The IELP is one of the largest and oldest English-as-a-second-language university programs in the state of Oregon. The mission of the IELP is to help nonnative English speakers achieve their academic, professional, and personal goals by assisting them in acquiring the necessary knowledge and language skills (Portland State University, 2014).

\section{PARTICIPANTS}

The participant in this case study is a senior IELP instructor who started teaching ESL in the U.S. in 1997. She started teaching in the IELP as an adjunct, and soon became a full-time, fixed-term faculty member. She received her certificate in TESOL and a Master's degree from a four-year university ${ }^{1}$. Research suggests that as teachers develop into more experienced, better qualified teachers, they become better able to evaluate their own teaching (Sendan \& Roberts, 1999). Therefore, a study using a teacher who is experienced, as in this study, will likely lead to more accurate assessments from her about her own teaching. Permission to use the teacher's interview responses, observation notes, and video recording data in this study was obtained through a signed consent form completed by the participant.

\footnotetext{
${ }^{1}$ Details omitted to protect the identity of the participant.
} 
The initial pool of participants was a convenience sampling of IELP teachers who all volunteered to be part of the initial video data study (in which teachers were video-recorded to contribute to a corpus of videos of IELP teaching described in more detail below). The participant used in this study was selected from the group of other instructors for several reasons. She met the requirements of being a participant in the original study while continuing to teach in the IELP, and was thus available for this study. This teacher also had availability for an in-depth case study and expressed a willingness to participate in a study that involved multiple data collection sessions. This included the time commitment of numerous interviews, meetings, and classroom observations. Finally, of all the teachers who participated in the initial study, I knew this teacher best because I had previously collaborated with her in one of her classes. It was my hope that the selected teacher would feel more comfortable communicating with me than any of the other teachers because of our shared history.

\section{MATERIALS}

\section{Lab School}

The PSU ESOL Lab School is a national research center engaged in classroombased research and professional development focusing on ESL. It was designed to strengthen programs serving adult ESL learners across the country through educational research and experimentation within the context of existing ESL programs. Since 2005, the Lab School has recorded courses from Portland State's 
Intensive English Language Program as well as Portland Community College (PCC) classes. The Lab School is modeled after similar "lab schools" found in K-12 education. In these environments, an elementary or secondary school operates in partnership with a nearby university engaged in teacher preparation and educational research. These lab schools serve as settings where teacher preparation, educational research and program development can take place. Stephen Reder, prior director of the Lab School, described the goal of the Lab School as a collaborative endeavor to improve ESL programs in order to actively engage learners, teachers, and researchers, and better serve local, regional, and national needs. The Lab School at PSU has established a setting where applied research can be conducted cooperatively by university-based researchers, teacher trainers and service providers (Reder, 2005).

\section{Multimedia Adult English Learner Corpus}

One data source for the present study is the Multimedia Adult English Learner Corpus (MAELC), a collection of audio-visual recordings available through the Lab School. This data consists of classroom interactions between ESL learners working collaboratively and between teachers and ESL learners in the classroom (Reder, Harris, \& Setzler, 2003). The classrooms were equipped with video cameras and students were given wireless microphones; the teacher wore a microphone at all times (Reder, Harris, \& Setzler, 2003). The videos were organized by academic quarter. Fall 2007, in which the participant was teaching Level 1 Grammar/Writing, 
was selected for the present study. This term was chosen because it was the second quarter in which the teacher participated in the video recordings and she was teaching a class of low-level learners, just as she was in her 2015 class. I hoped the teacher would be more used to the process of filming than in her first term participating, and her teaching in the videos would therefore be more reflective of her authentic teaching at that time.

According to Reder, Harris, and Setzler (2003), the project has developed specialized software called ClassAction, a set of interrelated software programs, to attach activity and content codes and transcriptions of classroom language to the multimedia corpus. The corpus videos can be viewed using Toolbox, one of the ClassAction programs. The Toolbox program is a data management and analysis tool for field linguists. It can be used to view synchronized camera views with audio and to view, enter, and edit associated codes, transcripts, and annotations. Toolbox provides a way to save and organize the corpus videos for researcher viewing (Reder, Harris, \& Setzler, 2003). For this research, I was able to gain access to Toolbox and the corpus by making an inquiry to a Lab School administrator.

\section{DATA COLLECTION PROCEDURES}

Three forms of data gathering were used in order to capture and compare the fluidity of change over time: in-depth semi-structured interviews, classroom observations, and stimulated recall, following the data collection procedures used in previous studies of teacher cognition by Kang and Cheng (2014), Woods (1999), and 
Zheng (2013). This allowed the teacher participant's changes in cognition to be analyzed in a variety of different ways. The study took a dual approach: first, I looked at previous research on teacher cognition and the video data of the focal teacher and used these sources to prepare the initial interview questions. Second, additional interview questions were structured around the teacher's responses to previous questions. This served as a way of letting the teacher participant provide data about what she has noticed in terms of change, rather than only what I observed. This method was based on studies (by Kang and Cheng (2014), Kuzborska (2011), Wong (2013), and Zheng (2013)) that used dual approaches. As Kang and Cheng (2014) describe, "the data collection process was cyclical in nature, with each successive stage being influenced by the analysis of the data already collected" (p.174). Data collection took place over the course of a 10-week academic quarter $(1 / 5 / 15-3 / 15 / 15)$. I observed and/or met with the teacher a total of ten times, including the pilot stage.

Pilot Stage

As outlined in Wong (2013), there was a pilot stage before the 10-week period of data collection in 2015. Two classroom observations of the teacher were conducted in 2014. These observations were designed to collect base-line data for preliminary areas of focus and interview questions. I also watched several lab school videos of the teacher participant throughout the Fall 2007 term to inform questions for stimulated recall interviews. These videos and observations of the 
classroom were iteratively examined together in order to identify aspects of teaching to focus on and to inform possible areas for further investigation in subsequent interviews.

\section{Video-Stimulated Recall}

Stimulated recall methodology is an introspective method of prompting participants to recall thoughts they had while performing a task or participating in an event. This is accomplished by presenting the participant with a visual or aural stimulus to aid them in recalling details of the event itself. As a result, a research subject may be able to relive the original situation vividly and accurately, recalling their cognitive processes during the event (Mackey \& Gass, 2000). Stimulated recall interviews can be used to elicit teachers' thoughts or beliefs underlying specific practices and to help them recall details of teaching sessions that they might otherwise not be able to do (Kuzborska, 2011; Zheng, 2013).

Stimulated recall interviews are usually conducted immediately after the event (Mackey \& Gass, 2000). However, in this study, a type of delayed stimulated recall was used in which selected videos of the participant's teaching from eight years ago were watched between the teacher participant and the researcher and a follow-up interview was conducted after each viewing. Despite the limitations of the timing of the videos, stimulated recall was selected as a data collection method for this study because I believed the Lab School videos were a rich and unique source of possible data. The goal of this study was to examine development over the career 
span and I believed watching and discussing the videos together could be a useful method of obtaining data about the teacher's cognitions from that time. As Borg (2006) discussed, stimulated recall can be used as "the basis of concrete discussions of what the teachers were doing, their interpretations of the events represented in the stimuli and of their reasons for the instructional decisions they were taking" (as cited in Kuzborska, 2011, p. 107). Given that the focus of the present study was possible changes over time, I decided to use stimulated recall as a data collection procedure because of the high quality of data that could be obtained by using the video stimuli. I predicted that this method would enable the teacher to recall aspects of her teaching from many years ago and be more confident in her ability to respond accurately to questions about her previous teaching.

\section{Observations}

Observations allow the researcher to be immersed in a research setting and systematically witness various dimensions of that setting. They have the advantage of allowing the researcher to collect large amounts of rich data on participants' behaviors and actions. Longitudinal, repeated observations allow the researcher to gain a deeper understanding of the context and participants (Mackey \& Gass, 2005). Observations do not give the researcher access to the participant's' motivation for their behaviors (Mackey \& Gass, 2005). For this reason, this study combined observations with the other techniques detailed in this section. 
Four classroom observations were conducted, two without interviews and two followed by interviews with the teacher participant. The purpose of these observations was to examine the teacher's style of teaching and look for salient features and particular interactions with students to use in further interviews and analysis. By asking interview questions after observations, I was able to ascertain the teacher's rationales for certain pedagogical choices and how she felt about particular classes. Detailed field notes were made during the observations, outlining descriptions of the teaching steps and student behavior during the lessons, the teacher's interactions with students, my impressions and questions, and any other notable aspects of the lesson (Wong, 2013). All the post-lesson interviews were held immediately after the classroom observations.

\section{Interviews}

Six open-ended and semi-structured interviews with the teacher participant were conducted: a background interview, two stimulated recall interviews, two semi-structured interviews following observations, and a final interview to answer remaining questions. Interview questions were based on 1) themes, models, and dichotomies that surfaced in relevant previous literature, 2) apparent changes or lack of changes based on classroom observations and my previous viewings of the Lab School videos, and 3) themes emerging through interviews, such as responses that occurred repeatedly and ideas that indicated possible changes or consistencies that the teacher seemed open to discussing. Open questions were mostly used to 
allow the teacher opportunities to develop her replies in ways which I might not have foreseen. Examples of these types of questions related to change over time include: Do you notice areas in which you think your teaching has changed? and Is there anything you notice that you continue to do while teaching? These openended questions were prepared prior to the interview session and additional questions were asked if relevant to the participant's response (See Appendix). All interviews lasted between 30 and 90 minutes and were audio-recorded. An audit trail of the date of each interview was used to keep track of these occurrences. Details about each type of interview are presented below.

1. Background Interview:

Before discussing areas of the video, I conducted a background interview with the teacher to gain information about her teaching history. These initial interview questions were more structured and explored the questions of why the participant decided to pursue teaching as a career, what her experiences were like as a student (in secondary school, college, and in teacher education), and how they have affected her teaching from a beginning teacher until today.

2. Stimulated Recall Interviews:

Two of the interviews used in this study were stimulated recall interviews. I first watched several Lab School videos from Fall 2007 during the pilot study. These video observations, as well as subsequent classroom observations, helped to inform 
which videos I selected for each interview. Before each stimulated recall interview, I watched the videos again and selected a few excerpts from one or two videos to watch with the teacher. To be comprehensive of the teacher's development throughout the term, I used portions of videos from the beginning of the term in the first stimulated recall interview and the end of the term in the second interview. Because the classes were two hours long, it was not feasible to watch the whole video with the teacher. I looked for portions of the class in which the teacher instructed the students or interacted with them. I excluded occasions in which students were working silently or in small groups. I selected portions of the videos in this way so that the participant could see and evaluate her own teaching, rather than the students' participation in class. After watching portions of the classes from 2007 with the participant, she was asked about various aspects of each teaching session. As discussed above, these interview questions were designed to elicit the teacher's responses to her teaching and explore how her teaching has changed or remained constant over time. Examples of stimulated recall questions include: How do you feel about this particular lesson? and Does anything stand out to you in terms of how you're teaching here vs. today? After stimulated recall interviews, responses were examined and questions were prepared for subsequent interviews.

\section{Semi-Structured Interviews:}

Two interviews were conducted following in-person observations of the teacher's classes in 2015. These interviews were less structured than the 
background and stimulated recall interviews. Following the structure used by Kang and Cheng (2014), I observed the teacher's current teaching, prepared some questions based on what I observed, and discussed my observation notes with the teacher immediately after the lesson. I began these interviews by asking the participant to comment on her lesson plan for the day and her thoughts about the class, followed by questions seeking her explanations for specific teaching moments or interactions. I then asked additional questions that had been prepared ahead of time. I compared the interview notes to the previous interviews to look for trends emerging in the data, and focused on those aspects in preparing questions for additional interviews (See Table 1). A final interview was conducted to answer the remaining questions I had accrued and clarify any ambiguities from previous interviews.

\section{Previous Literature}

Two studies that focused on changes in teacher cognition over time helped to shape initial interview questions. The model proposed by Fuller (1969) outlines a picture of teacher change in which teachers progress from concerns about the self to task concerns to impact concerns. The degree to which this teacher progressed through these stages was believed to be a possible area to start analyzing changes. I looked for categories within each stage (self concerns, task concerns, and impact concerns) to prepare interview questions about teacher concerns. The second study which informed questions was Zheng's (2013) study of changes in beliefs, in which 
he outlined the following "belief codes": beliefs about ESL; beliefs about ESL teaching; beliefs about ESL learning; beliefs about ESL learners; beliefs about ESL teachers. These five categories of teacher beliefs served as a starting point for discovering the teacher's belief system and how it may have developed. These two studies were chosen as starting points for interview questions because they examine development over time through the lens of two aspects of teacher cognition: beliefs and concerns. In Interviews 2 and 3, questions were formulated based on the findings from these studies and other interview questions were formulated based on the teacher's responses (See Table 1).

Table 1: Summary of Data Analysis and Recurring Themes

\begin{tabular}{|c|c|c|}
\hline Interview \# & Topic of Interview & Themes that emerged from interview \\
\hline 1 & $\begin{array}{c}\text { Background; } \\
\text { teacher training } \\
\text { experiences }\end{array}$ & $\begin{array}{c}\text { Differences between teaching as a beginning and } \\
\text { more experienced teacher; culture of service; } \\
\text { empathy; authenticity; confidence }\end{array}$ \\
\hline 2 & $\begin{array}{c}\text { Teacher concerns } \\
\text { Classroom management; curriculum; intuition; } \\
\text { changes in the teacher's concerns; empathy; } \\
\text { teacher's environment; context }\end{array}$ & $\begin{array}{c}\text { Teacher's belief system; empathy; belief } \\
\text { development; changes in teaching presentation; } \\
\text { curriculum objectives }\end{array}$ \\
\hline 3 & $\begin{array}{c}\text { Beliefs and changes } \\
\text { in beliefs } \\
\text { Classroom }\end{array}$ & $\begin{array}{c}\text { Understanding of low-level learners; structure of the } \\
\text { class; classroom discipline; lateness; 'unengaged' } \\
\text { students; routines; context }\end{array}$ \\
\hline 5 & $\begin{array}{c}\text { Context; teaching } \\
\text { philosophy; } \\
\text { reflections on } \\
\text { teaching }\end{array}$ & $\begin{array}{c}\text { Teachers environment; importance of context; } \\
\text { changes in the teacher's attitude and practices; } \\
\text { teacher's knowledge of students; empathy }\end{array}$ \\
\hline 6 & $\begin{array}{c}\text { Curriculum; teacher } \\
\text { knowledge; } \\
\text { teaching strategies }\end{array}$ & $\begin{array}{c}\text { Teaching context; knowledge of curriculum; fluidity; } \\
\text { modifying teaching based on student feedback }\end{array}$ \\
\hline
\end{tabular}




\section{Timing of Data Collection}

In 2014 , in the term prior to the term of data collection, I conducted a pilot study as described above. The data collection for the actual study included the following steps: first alone and then together with the teacher, I watched two Lab School videos from the 2007 class, one from the beginning of the term, and one from the end of the term and conducted a stimulated recall interview based on each video. I attended four classes the teacher taught in 2015 at different times throughout the term: during the beginning, middle, and end of the term, and conducted interviews following two of those observations. By doing observations and interviews at different times throughout the term, the data is representative of the teacher's style of teaching at different times during the length of the course. At the beginning of the term $(1 / 8 / 15)$, I met with the teacher to make a schedule of when interviews and observations would take place. For the most part, one data collection procedure took place every week. Two interviews had to be rescheduled and moved to the following weeks because the teacher had a conflict (See Table 2).

Table 2: Schedule of Data Collection

\begin{tabular}{|c|c|}
\hline Type of Data & Date \\
\hline Pilot Classroom Observation of a 2014 class & $11 / 28 / 14$ \\
\hline Pilot Classroom Observation of a 2014 class & $12 / 5 / 14$ \\
\hline Observation of a 2007 Lab School Video & $12 / 8 / 14$ \\
\hline Classroom Observation 1 of a 2015 class & $1 / 12 / 15$ \\
\hline Background Interview 1 & $1 / 15 / 15$ \\
\hline
\end{tabular}




\begin{tabular}{|c|c|}
\hline Classroom Observation 2 of a 2015 class \& Interview 2 & $1 / 23 / 15$ \\
\hline Observation of a 2007 Lab School Video & $1 / 28 / 15$ \\
\hline Stimulated recalla Interview 3 & $1 / 29 / 15$ \\
\hline Classroom Observation 3 of a 2015 class & $2 / 2 / 15$ \\
\hline Classroom Observation 4 of a 2015 class \& Interview 4 & $2 / 13 / 15$ \\
\hline Observation of a 2007 Lab School Video & $3 / 2 / 15$ \\
\hline Stimulated recall Interview 5 & $3 / 3 / 15$ \\
\hline Final/wrap-up Interview 6 & $3 / 10 / 15$ \\
\hline
\end{tabular}

${ }^{a}$ Note. All stimulated recall interviews were based on the Lab School videos from 2007.

Summary

To summarize the data collection procedures: first, I watched videos of the teacher from eight years ago and did two pilot observations of her current teaching. Next, questions were formulated based on these viewings and research from previous literature. Then, data was collected about the teacher's cognitive development using stimulated recall, interviews, and observations. Interview questions were shaped by previous studies and in response to the trends that emerged from the participant's responses.

\section{DATA ANALYSIS PROCEDURES}

In exploring the teacher's cognitive development through analysis of the three data collection methods, a deductive approach was combined with an inductive approach, as outlined in Kuzborska (2011). The data was analyzed in an exploratory manner to avoid either imposing prior categories of analysis or 
prematurely forming such categories without enough data (Wong, 2013). An iterative process was used whereby each stage of data analysis informed the subsequent stage of data collection.

Qualitative research often changes course as a study progresses based on the findings from the data (Mackey \& Gass, 2005). Therefore, the research questions guiding this study changed several times based on the data I collected. The original goal of this study was to understand something about the changes that occurred in a teacher's cognitions through the course of her career. I planned to choose a specific area within teacher cognition to focus on based on the data I got from the pilot study and the initial interviews. As data collection continued, it seemed that teacher expertise encompassed many aspects of the teacher's development, as topics seen in findings from previous studies of teacher expertise emerged many times during our discussions. Therefore I decided to use teacher expertise as a lens to analyze this teacher's development over time. I deliberately did not mention 'teacher expertise' during interviews so as to not influence the participant's responses in any way. After transcribing and taking notes on the audio recordings of the data, I gave the written notes to the participant to look at and correct any fallacies or misinterpretations she perceived.

Following the analysis procedures of Kang and Cheng (2014), I first listened to the recordings of interviews multiple times and loosely transcribed the text. After reading the transcripts in detail and noticing which themes had emerged, I coded 
the teacher's responses using the teacher expertise categories from Tsui (2003) and Farrell (2013). The following categories were used as initial teacher expertise codes of analysis from Tsui (2003): ability to integrate and use different kinds of knowledge; desire to solve a wide range of teaching problems; management of learning; ability to make intuitive judgments and teach with fluidity and automaticity; greater awareness and understanding of the learning context and students' needs; understanding of language learning strategies; and awareness of instructional objectives and the curriculum. Farrell (2013)'s study of teacher expertise used the following five codes: knowledge of learners, learning and teaching; engagement in critical reflection; accessing prior experiences; informed lesson planning; and active student involvement (Farrell, 2013).

Next, I analyzed and organized the prevalent codes I found according to changes and consistencies the teacher described. The four areas of language teaching which novice teachers were less skilled in Richards, Li and Tang's (1998) study (thinking about the subject matter from the learner's perspective; having a deep understanding of the subject matter; knowing how to present subject matter in appropriate ways; and knowing how to integrate language learning with broader curricular goals) were used as initial codes of analysis for examining development over time. Thus, the coding was conducted both "deductively using a priori categories derived from the literature, and inductively by identifying the concepts that formed these categories as they emerged from the data" (Kang \& Cheng, 2014, p. 174). I analyzed the data through these initial codes, which served to generate 
further ideas to be explored and to identify emergent thematic elements (Harklau, 2000). I reformed some of the codes to be more representative of the information I found in the data sources. Thus, the most comprehensive codes were adapted to best characterize the trends found in this data (See Table 3). 


\section{CHAPTER 4: RESULTS AND DISCUSSION}

\section{INTRODUCTION}

This chapter will discuss the results of the study. First, the background of the teacher used in the study will be described. Next, I will discuss the development of the teacher over time and aspects of her teaching that have changed and remained constant as demonstrated by the data sources. The teacher expertise codes used in the analysis can be seen in Table 3.

Table 3: Summary of Analysis Codes based on Findings from Data Sources

\begin{tabular}{|c|c|}
\hline Aspects of teaching that indicated change & $\begin{array}{l}\text { Aspects of teaching that did not indicate } \\
\text { change }\end{array}$ \\
\hline $\begin{array}{l}\text {-Teaching with fluidity, automaticity, } \\
\text { and intuition } \\
\text { •Confidence } \\
\text {-Concerns } \\
\text {-Management of teaching enthusiasm } \\
\text { and relationships with students } \\
\text { - Support and validation from colleagues } \\
\text {-Managing the classroom for learning }\end{array}$ & $\begin{array}{l}\text { - Beliefs and teaching philosophy } \\
\text {-Reflection } \\
\text { - Learning from past experiences } \\
\text {-Knowledge of lesson planning and } \\
\text { curricular goals } \\
\text { - Students' needs within the learning } \\
\text { context }\end{array}$ \\
\hline
\end{tabular}

The teacher's changes and consistencies will be discussed in terms of her development of expertise, their relevance to previous literature, and the research questions: 
1) What changes does an experienced academic ESL teacher report in her teaching over a period of eight years and how have they impacted her teaching?

2) How does expertise evidence itself in this teacher's changes or lack or changes in cognition (knowledge, beliefs, and attitudes)?

These questions will be discussed together because as Tsui (2003) says, the professional development of teachers "cannot be discussed separately from the factors that shaped their development, and hence the development of expertise" (p. 245). Furthermore, Farrell (2013) states that the characteristics in his study of ESL teacher expertise "should be seen in a holistic manner because they are not isolated as each is linked to the other and each builds on the other" (p. 1079). The name 'Rebecca' was chosen as a pseudonym and some details were omitted to protect the participant's identity.

Rebecca's teaching has developed over the course of her many years as an ESL instructor. Her experience is grounded in a strong basis of pedagogical and content knowledge and many years of practical experience, yet Rebecca is not just an experienced teacher. This paper will describe how Rebecca has become an expert teacher through her development over time.

\section{REBECCA'S EDUCATIONAL BACKGROUND}


As I learned from the initial background interview, Rebecca has been teaching in the IELP at Portland State University for 15 years. She started as an adjunct but was hired full time two years later. She felt that she would become either a teacher or a nurse because they were the models around her as she grew up. Rebecca became more interested in the profession of teaching because she had always enjoyed English and language arts classes and ended up majoring in English as an undergraduate. She initially decided to focus on ESL because it was something practical to do with an English degree. Rebecca studied at a private university which emphasized a culture of public service and giving back. It required students to do a service learning project and Rebecca chose to go to China and teach English. As her first experience teaching English, it helped her realize she was interested in the field. She completed her TESOL certificate and a Master's degree and spent several years teaching abroad in Japan. She admitted, "Everything that I learned when I got my degree seems a bit outdated now" (Interview 1:1/15). Since then, she has attended TESOL conferences and workshops, has participated in focus groups and book clubs, and has observed colleagues' classes to improve her understanding of the TESOL field. Rebecca also has several years of experience in teacher education.

Rebecca has studied Spanish and some Japanese. For her, the experience of learning a second language has been fun but challenging and has helped her develop an understanding of the challenges of language learning including how long it takes to become proficient and the differences between proficiency in productive and receptive skills. As she draws on her experiences learning a second language, she 
incorporates empathy into her approach to teaching: "Learning a second language really helps you understand teaching because you know what it's like to be on the other side of the desk" (Interview 1:1/15). Rebecca aims to put herself in the learner's position - to think about what she would want or need in that position to attain proficiency in a language.

\section{DEVELOPMENT OVER TIME: CHANGES, MODIFICATIONS, AND ADJUSTMENTS}

These following categories were found to be prevalent in the data and were selected for analysis for both their widespread appearance in the data and the fact that they had previously been documented in prior studies. Rebecca's views of her changes over time were characterized by six main themes:

- Teaching with Fluidity, Automaticity, and Intuition

- $\quad$ Confidence

- $\quad$ Concerns

- $\quad$ Management of Teaching Enthusiasm and Relationships with Students

- $\quad$ Support and Validation from Colleagues

- $\quad$ Managing the Classroom for Learning

Teaching with Fluidity, Automaticity, and Intuition

According to Dreyfus and Dreyfus (1986), expert teachers are more effective in handling classroom events, more discerning and better able to improvise. Furthermore, expert teachers have been described as "having the ability to perform 
with 'automaticity', 'fluidity', and 'effortlessness'" (Tsui, 2003, p. 268). This aspect of expert teaching stood out during discussions of Rebecca's teaching. When she started teaching, Rebecca was initially really scared because she doesn't like public speaking. "I had to get out of my own head and learn to really be there for the students" (Interview 1:1/15). As a less experienced teacher, she explained feeling "married to the lesson plan" and that she struggled to be spontaneous in the classroom. For these reasons, she had a tendency to rush through her lesson plans too quickly because she struggled with being able to relax, trust herself and go deeper with the lesson material. "Slowing down and believing in the process was the biggest challenge for me" (Interview 1:1/15). This was characteristic of her style of teaching as a non-expert.

Further explanations of her teaching made it clear that automaticity and fluidity developed in Rebecca's later teaching. Now, Rebecca can easily make decisions and judgments based on intuition. For example, she explained that she thinks about the impact she might have on her students "subconsciously, to make the class interesting and fun, and to help them see the value of certain things" (Interview 2:1/23). After an observation of one of Rebecca's classes, in which she decided to give the students a break earlier than planned after a group activity, Rebecca described the choice: "It felt naturally like a good time to close. Some of them needed more time to work on their homework. I'm better at doing it than explaining it" (Interview 2:1/23). This account of unconscious decision-making shows that Rebecca naturally knows the best pedagogical choices for her students. 
Rebecca also indicated fluidity and automaticity in her teaching when she described how she prepares students to know what to expect in class and how to do certain activities. "I used to do more scaffolding in the past when I taught other classes, but now I feel like I've just gotten into a groove and if they seem to get it, I kind of just go with it" (Interview 2:1/23). Additionally, she describes the way she gives instructions and introduces activities as, "It's kind of about finding a groove, a comfort zone, and a harmony in the classroom. I try to find ways to do that. I try to give a lot of examples, but I also try to give students time to ask questions" (Interview 2:1/23). Furthermore, when asked how she makes sure she gets through everything required in the curriculum, she replied,

There are certain things they need to be able to do to be successful in the next level that I hit early and I hit often. I don't go through it check mark by check mark so I won't leave out something really important. It's a more circular approach. But that's because I've been doing it a lot and I know my rhythm. (Interview 6:3/10)

These examples further show that Rebecca's teaching has become fluid and automatic. She knows how to be successful in the classroom because she has the experience to know her "groove" or "rhythm" as she explains it, that makes her feel fully embodied in the role of teaching. This supports the Dreyfus and Dreyfus model of expertise, that experts have achieved such a high level of ease and intuitiveness in 
their area of expertise that they cannot adequately articulate how they do something - they simply do it well.

Tsui (2003) described a teacher she considered an expert, Marina, and found that Marina did not fit this particular characteristic of expertise. Marina made very deliberate choices while teaching and didn't describe her experience in the classroom as automatic and effortless. However, in Rebecca's teaching, she demonstrates that she follows this aspect of the Dreyfus and Dreyfus (1986) model. Her description of the "groove" or "rhythm" that she falls into when teaching clearly articulates intuitive actions. Rebecca also seems to have a hard time describing how to characterize her sense of ease with teaching, as when she said, "I'm better at doing it than explaining it" (Interview 2:1/23). These examples show that a sense of "automaticity" or "fluidity" is a part of Rebecca's expertise in teaching. These findings are corroborated by Farrell (2013), who concluded that his expert teachers "showed that they possess the ability to make intuitive judgments based on their combined past experiences...but that it is not just blindly following these past experiences but doing so in a professional manner" (pp. 1076-1077). Thus, it appears that having and maintaining an intuitive sense of how to proceed in a given teaching situation can be an aspect of teaching expertise.

\section{Confidence}

As Rebecca gained more experience, she began to develop a greater understanding of how to be an effective teacher. This gave her more confidence in 
herself as a teacher and in her ability to effectively help students. Describing her present teaching, she said, "It's more fun now. I'm into the experience and am present with it. If something takes things in a different way, that's fine with me. I'm happy to go with the way the students are taking things. I know we'll get back on track" (Interview 1:1/15). As a result of her increased confidence, Rebecca finds the experience of teaching itself much easier now. She noted that as a teacher, "I feel thoroughly embodied when I'm in that role. I feel that I'm the person to help them in that situation. Before, I wasn't sure and I felt more fragile. Now I'm more authentic" (Interview 1:1/15). Rebecca's confidence in herself has made her teaching improve because she has greater enjoyment of teaching, better understands what is effective in the classroom, and has become a more authentic educator.

As a beginner, Rebecca didn't feel comfortable moving away from the lesson plan because she didn't have the confidence to know that the class would get back on track. "I know that I have the tools to help the students and I used to just be married to the lesson plan because I wasn't sure. I couldn't veer from it because I didn't have the confidence" (Interview 1:1/15). Now, because her confidence has increased, Rebecca is more willing to depart from the specifics of the lesson plan in order to meet the students' needs. "I'm a lot more relaxed and a lot more confident because I've had experience to know that we don't have to stick to the plan" (Interview 1:1/15). This improved confidence has led greater effectiveness and a calm demeanor to characterize Rebecca's present teaching. Similarly, Farrell (2013), reported that among the expert teachers in his study, "over the years, their views 
towards lesson planning have changed" (p. 1078). They too were more willing to adapt if the lesson took them in a different direction (Farrell, 2013).

Through our interviews, it became evident that Rebecca's confidence and ease in the classroom have increased as she has gained greater experience as a teacher. This is something she noticed during a viewing of one of the videos of her teaching from eight years ago. She noticed,

I feel like I'm saying a lot of information. And I'm checking in with them and speaking pretty clearly, which I would still do, but it feels like I'm talking a little bit faster than I do now. And I'm repeating things because I'm not sure they understood it whereas now I might just choose my words more carefully and speak a little more slowly and clearly. Now I feel like I would speak a little more calmly, slower, and confidently. Maybe not saying 'so' as much or having to repeat myself as much. (Interview 5: 3/3)

Rebecca clearly saw differences between her teaching at the time of the videos and her teaching now and attributed this to her increased confidence. To account for the factors that may have contributed to these changes, she explained,

I feel that I have a little bit different style now in terms of being more relaxed and that helps me think a little more about what I'm going to say and be able to say something a little more effectively...I think it comes from experience, 
positive feedback, learning by trial and error, and confidence, which has allowed me to present a calmer demeanor. (Interview 5:3/3)

This demonstrates a positive development over time in which Rebecca has become more calm, confident, and relaxed in the classroom and this in turn has helped her better explain concepts to her students.

\section{Concerns}

As previously discussed, Fuller (1969)'s model of teacher development describes three phases of pedagogical concerns. During early field experience, prospective teachers become concerned about their survival as teachers (self concerns). As they continue in teacher preparation, their concerns focus upon their actual performance as teachers (task concerns). Finally, after having successful teaching experiences, more mature teachers' concerns focus on having a meaningful and positive impact on their students (impact concerns). When responding to the question of whether she is concerned about what students think of her, Rebecca replied,

I certainly want their respect and I want to present myself as someone who is capable, knowledgeable, and has the resources to give them what they need. I want them to trust me and not doubt my ability. That is a concern, but I don't care so much if they think I'm the best teacher or cool, and I don't worry about them seeing me out in the world. (Interview 2:1/23) 
This shows that Rebecca has moved out of the phase of self-concerns consistent with inexperienced teachers, because she is less concerned with how her students' view her personally and instead focuses on students' views of her professional skills. Thus, she wishes to be seen as effective, but is more concerned with the students' understanding (impact concerns).

As part of the questions prepared about task concerns, Rebecca was asked if she is concerned about whether she will experience problems with students who are misbehaving or pushing boundaries. She responded that she doesn't worry about it anymore. If it happens, she is able to respond to it, but it hasn't been too much of an issue. Rebecca has learned that if you establish an environment of respect, student behavior doesn't become an issue. She also doesn't worry about students who are absent or late anymore. She has routines for handling students who are consistently late, such as talking to them after class about why they are late or if there is anything outside of class affecting their attendance. However, she doesn't feel that she has to handle everything alone. “We have a supportive family here so I feel like I have people to go to if I do have an issue. We have the academic director, the student counselors, SHAC [Student Health and Counseling Center], for example" (Interview 2:1/23). This shows that Rebecca has an extensive understanding of the resources that are available to her in the IELP and knows how to reach out to the people in place to support her. Rebecca is no longer concerned about task concerns that might worry less experienced teachers, such as difficult students or managing attendance and tardiness issues. She has developed the 
knowledge and experience to understand her teaching environment and how to handle her classroom such that she can now focus on more complex, higher-level teaching concerns.

Rebecca's responses to questions about what concerns her in teaching demonstrates that she has moved through self concerns and task concerns, but now has a stronger focus on impact concerns. While she still thinks about teaching tasks related to performing her job well within the curriculum constraints (task concerns), she doesn't worry about it.

I think I've always had some of the same concerns since it's a curriculum guided program. I was also pretty concerned with not messing up when I first started because good reviews matter. I didn't want to do anything that made the students not like me. I wanted to make sure they were happy. Now I'm more concerned with making sure the students are getting what they need. (Interview 2:1/23)

This data indicates that Rebecca has moved past concerns about herself to concerns about the impact her class has on her students' educational development and how they relate to her as a professional.

Management of Teaching Enthusiasm and Relationships with Students

During a stimulated recall interview, Rebecca acknowledged that she had experienced feelings of burnout at the time of the videos. She noticed that her 
teaching during one of the videos appeared less relaxed and self-assured, and this may have been due to feeling less enthusiastic about teaching overall. When asked how she deals with potential teacher burnout today, Rebecca responded that it's no longer something that she has to work on.

When I come to class, I feel really excited about it. I'm energized by it. I'm lucky; I really like all aspects of my job. That wasn't always the case. I have gone through periods of burnout in the past, where I didn't want to teach in the summer but I needed the money. I used to dream about having time to do other things. But somewhere along the line, I just made a shift. I had more freedom to teach courses I wanted to teach - I think that was part of it. I had less stress because I already had lesson plans ready to go. Also becoming more confident in the classroom and developing relationships with my students helped me and it was kind of a cycle. I did a lot of personal growth too and I think I got to a place where I was happier in general, and I think I can make choices so just being more positive in general. (Interview 5:3/3)

It is clear that Rebecca experienced feelings of teacher burnout in the past but she was able to improve her attitude about herself as a teacher. Greater confidence, freedom to make choices, and a changed attitude have all helped Rebecca overcome teacher burnout and maintain effectiveness and passion for her profession. This is consistent with the findings of Yazdi et al. (2014), who found that teachers' selfefficacy has a reverse relationship with burnout. 
Farrell (2013) discussed teachers' levels of active engagement with their jobs and their students in his characterization of what makes an expert ESL teacher. An important part of their professional practice is going beyond the classroom. "Active student involvement is an indication that the teachers care about their students and this has been seen to have a positive influence on student motivation, participation and learning" (Farrell, 2013, p. 1078). Likewise, Rebecca stated that part of her teaching philosophy is about building community among her students.

One way to build community is to level the room. And one way to do that is to lower yourself a bit and let yourself learn from them. So I don't always plan for that but if I see an opportunity, I try to do that. I think that leveling the class lowers the affective filter because I'm not in this authority position all the time. So, one way to do that is to let them teach me something. (Interview $2: 1 / 23)$

Similarly, in Farrell (2013), one expert teacher said that "their professional practice as ESL teachers' goes beyond the classroom, our relationships. It's part of creating a whole environment for them and building a community for them" (p. 1079). His research indicates that teachers who feel less engaged with their students are more likely to feel dissatisfied with their teaching jobs. By building a community of learners, Rebecca has allowed herself to actively engage with her students and improve their learning environment. This has helped her build relationships with students and maintain enthusiasm for her job. 
Within any profession, including teaching, there will always be issues or conflicts that arise. How an individual chooses to respond to these problems is an indication of their development as a teacher. Rebecca's development of increased enthusiasm for teaching when faced with potential burnout indicates that she has in fact recognized conflicts in her teaching, thought about possibilities for change, and tried solutions to improve. Likewise, Tsui (2003) states that in her expert Marina's teaching, there was a relationship between developing confidence and increased enjoyment of teaching and a greater desire to improve as a teacher. As studies have shown, greater belief in their self-efficacy causes teachers to be more open, less critical, and more resilient in the face of setbacks (Hoy \& Spero, 2005). Tsui (2003) further argues that one of the differences between an expert and a non-expert was their disposition to challenges - the expert "responded positively to challenges by seeing them as opportunities to improve herself" while the non-expert "tried to reduce their complexities and by so doing, minimized her opportunities to further develop her capabilities" (p. 276). When confronting the problem of feeling burned out and considering a career change, Rebecca did not shy away from this challenge or give up on teaching. She made a shift in her attitude that helped her become a more effective and positive teacher, which in turn made her feel more excited and passionate about teaching. Bereiter and Scardamalia (1993) argue that expertise should be seen as dynamic because there are always opportunities to grow and continue developing as a teacher. However, some teachers are more open to these opportunities for change than others, and "see the conflicts, reflect on the 
possibilities, and try out the alternatives" (p. 270). This is part of what separates an expert teacher from a non-expert.

\section{Support and Validation from Colleagues}

Tsui (2003) argues that an important aspect of her expert teacher Marina's development of expertise included her positive interactions with others in her context of work. Marina consulted her colleagues, her principal, and participated in "the discourse communities of ESL professionals" (p. 280). Rebecca has clearly incorporated this important point into her own teaching. Rebecca stated that part of the reason she feels more confident in her work as a teacher is that she has been validated by her peers in the IELP. Her teaching evaluations were always good but she believes they're better now. Her peers have told her that they see her as someone who's really a leader in specific areas, such as curriculum design and vocabulary. "When you hear that it's really validating and it pushes you to keep being a leader. A lot of my confidence has come from that validation in and outside of the classroom from feedback from my peers" (Interview 1:1/15). Rebecca describes the people in her context of work as a "family," indicating that they are an important and supportive resource for her to grow as a teacher. This sense of support has given Rebecca the space to develop her teaching and feel motivated to take on greater responsibilities. Rebecca told me that this term she is part of the curriculum committee and is leading a focus group on vocabulary. The encouraging environment around her has helped Rebecca develop into an expert teacher because 
she feels more confident and motivated. Experiencing positive feedback and validation has had a positive impact on Rebecca's view of herself as a teacher and her desire to improve, which has in turn facilitated her development of expertise.

Gaining more freedom in her work environment has also given Rebecca the space to further develop her teaching. Rebecca told me that she now has more freedom to choose the classes she wants to teach because of the number of years she has taught in the IELP. "As I gained seniority I've had more freedom of choice and I've been able to teach the same classes and make materials for them. So I've gained some expertise in certain areas" (Interview 1:1/15). Because she is not concerned with having to prepare for a new class, Rebecca has the mental space to focus on developing more advanced teaching strategies and materials. Tsui (2003) writes that a teacher's whole environment plays a role in how they develop as teachers. A supportive environment can increase a teacher's ability to develop expertise, just as a perceived unsupportive environment can discourage it (Tsui, 2003). Experiencing support and validation and being given more freedom of choice have both made Rebecca's teaching environment more conducive to developing expertise.

\section{Managing the Classroom for Learning}

Rebecca demonstrated consistent knowledge of classroom management, or what Tsui (2003) describes as 'management for learning.' There are a variety of techniques she uses to help her students understand the expectations of the class. 
For example, she has a PowerPoint with classroom expectations that she uses at the beginning of the term. She also tries to review this PowerPoint before quizzes so the students remember the rules for quizzes. This reminds them of her expectations and makes it clear that cheating is unacceptable. Furthermore, she explained,

When I give homework, I try to be clear about how students can't do it in class, so they can give it to me half done or not give it to me at all. I'm not going to take it late. I try to show by example that in the IELP, this is what we do. It's part of my responsibility to prepare them for the higher levels. (Interview 3: 1/29)

This shows that Rebecca explicitly explains classroom management because she knows it is in the students' best interests to learn the expectations of the teaching context. Her style of classroom management is firm, but fair. She demonstrates clear pedagogical rationales for the decisions she makes in managing her classroom for learning.

Rebecca described how her classroom management style has changed over time. She used to be stricter and would take students' disruptions personally.

I used to be that kind of teacher who would tap the marker, stand quietly, flip the lights, etc. I've experimented with it over the years and I've found that little is better. Like if I'm yelling or saying "Come on", I don't know how effective that always is. I don't want to do things like say “Hey everybody, 
look at me" or "Students!" I want to be more mindful of whether they are learning by talking amongst themselves or whether they are actually getting carried away. (Interview 1:1/15)

Now she believes in treating students like adults and working to keep the students engaged so they will be less likely to get off task.

I don't like the idea of having to be a disciplinarian because I don't think that's how it works in the university setting. But I feel like I can and should hold my ground when I need to. I try to be fair and I try to show compassion. I feel like I'm an adult talking to other adults. I have more of a soft approach. If most people are on task, I don't want to make a big deal out of it. It's not that I can't, it's just not my style. (Interview 4:2/13)

This shows how Rebecca's style of classroom management has become more effective and efficient over the years, as she has gained greater experience.

During one interview, Rebecca demonstrated how various aspects of the changes she sees in her teaching have come together to make her a more effective teacher overall. In reference to bringing students' attention back to her in a class, she said,

Early on, I'd get a little frustrated. But now, I feel like I'm more relaxed and have a sense of humor and don't get all worked up. So raising my voice just a little bit is enough. And it does relate to confidence. I try to be gentle with 
them. Gaining more experience and comfort has helped. They're not doing it to be mean, they're just getting off track. So I might read the title of the story and just say it in a little bit louder voice. So, it came from experience, it came from trial and error, and also being more confident which has allowed me to be more compassionate. (Interview 1:1/15)

This shows that as Rebecca's confidence and ease have increased, her style of managing the classroom has improved. This in turn has helped her understand her students better, have a more compassionate attitude toward them, and therefore be more likely to actively engage and develop relationships with them. These changes, modifications, and adjustments over time are seen as a holistic series of developments that have facilitated Rebecca's development into an expert teacher.

\section{DEVELOPMENT OVER TIME: STAYING THE COURSE}

In addition to the changes demonstrated in the previous section, Rebecca's teaching has stayed relatively constant in several ways. This is not seen as detrimental to her teaching because finding a technique or way of thinking that works and being able to continue with it also indicates a high level of teaching. This aspect of Rebecca's teaching was characterized by the following five themes:

- Beliefs and Teaching Philosophy

- Reflection

- $\quad$ Learning from Past Experiences 
- $\quad$ Knowledge of Lesson Planning and Curricular Goals

- $\quad$ Students' Needs within the Learning Context

\section{Beliefs and Teaching Philosophy}

Rebecca described her beliefs as characterized by the roles of the teacher and the students and determined by contextual factors:

The teacher's role is to impart knowledge to the students - content knowledge and also strategies that will help them as future learners. It is the role of the teacher to determine which strategies work for which contexts. The students also have a role to play and that depends on the context. Basically, the role of the teacher is to prepare the students by imparting knowledge, including content and strategies. (Interview 3:1/29)

Tsui (2003) conceptualizes teacher knowledge as situated and integrated in a teacher's set of beliefs. If we see beliefs as integrated with knowledge, it seems that beliefs about teaching are highly specific to context and personal experiences. In her description of her own beliefs, Rebecca acknowledged that there is a relationship between her beliefs and the teaching context.

Rebecca reflected that her beliefs have remained relatively constant over the years. "I have the same core beliefs that I had back then but now I'm much more polished, much more filled out" (Interview 1:1/15). As we discussed her beliefs, Rebecca elaborated, 
I think I started off pretty naïve with kind of a blank slate and a lot to learn. I don't know that my beliefs have changed a lot because these things have all informed my belief system but I don't know that I had a strong belief system to begin with. It's more that I've grown in my belief system and it's gotten richer rather than I've changed. (Interview 3:1/29)

This shows that Rebecca considers her beliefs to have remained fairly consistent over the years and that she has simply developed deeper beliefs as she has accumulated experience. Woods (1996) states that each teacher's cognitive system of beliefs, assumptions, and knowledge (BAK) is interconnected, such that "a change in any one aspect will have an effect on other aspects" (p. 293). Thus, a teacher is not likely to change one belief without it affecting other elements of her belief system (Woods, 1996). Although she did not have a strong belief system as a beginning teacher, Rebecca's maintains that her beliefs have not changed significantly from the time of the videos until today. Therefore, Rebecca's development of expertise during this time did not seem to include a significant shift in her belief system.

Rebecca's teaching philosophy is characterized by empathy. She approaches teaching by putting herself in the learner's position and thinking about what she would want or need in that position to achieve language proficiency. She views teaching as a helping tradition. "I see my role as serving the students somehow" (Interview 1:1/15). This view of the importance of empathy began when Rebecca 
was a college student surrounded by a culture of service. Rebecca's prior experiences created a strong foundation for her philosophy of empathy in teaching, and this important view has not changed as she gained more experience. Rebecca explained how her philosophy of putting herself in the learner's position makes the learning environment more enjoyable and amenable to learning:

The chaos can happen and I'm okay with slowly reining them back. Again, I try to put myself in their situation. If I were in their situation, if I had a little more time to engage, I might be more open to understanding something and it would be more enjoyable for me. (Interview 2:1/23)

By putting herself in the learner's position, Rebecca is able to create a more relaxed and effective environment of learning for her students, which has in turn given her a greater understanding of her own students and what they need to succeed in the classroom. This parallels Tsui (2003)'s characterization of Marina, her expert teacher. "When she selected materials and designed language tasks and activities, she would put herself in the students' shoes and ask what they would like to do rather than what she would like them to do" (p. 251). In this way, both Marina and Rebecca are able to be effective teachers by putting themselves in the learner's position. Tsui (2003) characterizes this skill as an important aspect of expertise.

\section{Reflection}


Reflection is another way in which teachers can develop their teaching and grow into stronger teaching professionals. Rebecca has incorporated reflection into her practice as a teacher for many years. "I've found that for me reflecting works really well; reflecting on the classes and what I've done and how the students have responded has worked well. The reflective practitioner idea is something I stumbled on by working with graduate students" (Interview 3:1/29). As she is involved in teacher education, Rebecca has extensive experience with reflection. Rebecca's reflective practice is a skill she has been practicing for many years because she has found it successful in the past. It may be that involvement in teacher education has helped Rebecca become a more reflective practitioner. Likewise, critical reflection was also an expert characteristics outlined in Farrell (2013). He found that what all the expert teachers in his study had in common was "how they all engaged in some form of critical reflection and critical examination of their own practices" (p. 1075). Tsui (2003) also argued that "reflection and deliberation are characteristic of expertise" (p. 277).

It is interesting to note that as part of the original study in which the Lab School videos were made, Rebecca was asked to make a short audio reflection after each class. These reflections were included as part of the Toolbox software so I was able to listen to them. The reflections were mostly made up of short descriptions of activities that had been done in class and how Rebecca felt about the class. When I asked Rebecca about these reflections, she told me that she did not think she had put very much effort into them. She described feeling tired after teaching her 
classes, so she wanted to finish as quickly as possible. However, during the course of our interviews, Rebecca told me that she really enjoyed thinking about her teaching, discussing her classes, and reflecting on her previous teaching. This shows that while Rebecca has incorporated reflection into her teaching for many years, she has improved in her ability to reflect effectively. At present, she gets more enjoyment out of reflecting and this has further contributed to her development of expertise.

\section{Learning from Past Experiences}

Rebecca showed that the process of learning from past experiences is very valuable to her. She has continued to acquire knowledge over her many years as a teacher by attending conferences, professional development workshops, and participating in book groups with colleagues. Rebecca revealed that she has a lot of her own teaching strategies and routines that she has collected and that in the IELP,

we have a huge share drive. I feel like there's a wealth of activities. I have strategies that I can apply in different courses - like I apply vocabulary or pronunciation strategies in reading classes. I can adapt different activities to work with productive vs. receptive skills. I would say I definitely have a lot from teaching for so many years, writing myself notes, collecting things, having the share drive, going to workshops, etc. (Interview 6:3/10)

This shows that Rebecca has developed a wide repertoire of teaching strategies and activities from various experiences, including professional development workshops, 
activities shared among colleagues, and her own teaching experiences. In Farrell's (2013) study, his participants showed that they could make judgments based on their combined past experiences, such as knowledge from professional journals, conferences, and their colleagues' comments. Also, they all "seemed to have an extensive collection of routines and strategies from prior experiences to use in lessons" (Farrell, 2013, p. 1076). This is one of the aspects of the experts' teaching that helped to characterize them as expert teachers.

Rebecca uses specific routines in her class because she has learned from past experiences that they are effective in the classroom.

Routines are really important because it gives them [the students] something to expect and creates a good learning environment. One routine is to put the date and agenda on the board. We did the name cards until we learned everyone's names. At the beginning of a new chapter, I always give them a vocabulary list. That's part of my routine for a new chapter. (Interview $4: 2 / 13)$

This shows that Rebecca has learned from teaching experiences in the past how to implement successful routines in the classroom in order to improve the learning environment of the students. Farrell (2013) also found that his expert teachers were "able to call on a wide repertoire of routines and strategies when making instructional decisions" (p. 1077). One of these teachers said that "she makes use of her repertoire of routines according to her students' needs and her own preference 
as a teacher" (Farrell, 2013, p. 1077). Likewise, Rebecca explained her rationale for the routine of introducing a new chapter in the same way, as "It's kind of like a routine because then they're getting used to how content is introduced and I think that's good practice" (Interview 4:2/13). This shows that Rebecca uses routines to make new content easier for her students to understand. Thus, as Farrell (2013) describes, an ability to use routines and teaching strategies developed from prior experiences seems to be an important characteristic of teacher expertise.

\section{Knowledge of Lesson Planning and Curricular Goals}

Rebecca has a comprehensive understanding of the curriculum of which her learners are part and knows how to teach within it in order to meet curricular objectives. Rebecca described her lesson plans as using a combination of activities from the curriculum-mandated textbook and activities she has made herself.

In this class, they have two textbooks and I want them to feel like they've paid for something worthwhile. These two textbooks are good because there are activities where they can answer questions about their own lives. But if I think the class is getting too book heavy I'll sometimes use a different activity that I've created. (Interview 2:1/23)

This shows an understanding of the need to work with the materials provided by the curriculum while still wanting to incorporate other self-made activities in order to make the class interesting for the students. Rebecca's experience with teacher 
education may have also contributed to her strong understanding of lesson planning.

In our interviews, Rebecca often referenced the IELP curriculum or the curricular objectives of certain subject areas such as reading or grammar, as rationales for various pedagogical choices. "I'm concerned with whether they're learning and how to meet the guidelines of the curriculum...I think I've always had some of the same concerns since it's a curriculum-guided program" (Interview $2: 1 / 23)$. This shows that an understanding of the parameters of the curriculum has always been a consideration for Rebecca and an important part of her teaching. Farrell (2013) found that expert teachers "not only have mastery of their subject matter, but that they are able to manipulate it and present it in a variety of ways so that they can not only teach what they need to teach, but also keep their students happy" (p. 1075). Like the expert teachers in this study, Rebecca also considers her students' affects, such as when she plans different activities if the class is too bookheavy, as well as the constraints of the curriculum in order to make a positive and educational learning environment.

Rebecca revealed during our interviews that lesson planning has not changed very much in her teaching. She still plans detailed lessons because she wants to feel prepared for class.

I want to make sure I have thought about the previous lesson and reflected so I know where I'm going with the next lesson. I don't need as much time 
around the lesson now but I still want to make sure I'm building and paying close attention to what we didn't get to cover, what the students are still struggling with. (Interview 1:1/15)

This helps her know that she is adequately progressing through the curriculum and is able to fully meet the students' needs. She continues to devote a lot of time to planning lessons, just as she did when she was a newer teacher because she wants to thoroughly meet her students' needs.

I'm concerned with the students' needs and how to best meet them. I'm interested in tried-and-true ways and also new ways that might work for them. I guess that's why I put a lot of thought into my lesson plans. I don't always know students' expectations because students come from different cultures so it's hard to know what they expect, but I hope that I can meet their language needs. (Interview 2:1/23)

Likewise, Tsui (2003) reports that Marina, her expert teacher, never goes to class without preparation and a lesson plan because she would not be confident that the lesson would go well if she didn't. This indicates that for these teachers, part of what makes them highly competent instructors is their desire to make detailed lesson plans that ensure they will be prepared.

Students' Needs within the Learning Context 
Rebecca often demonstrated an understanding of the intricacies of the IELP learning context and how to respond to her students' needs within that context. We discussed her approach to a class and how it depends on the context and the type of learners in a particular class.

I also try to encourage spontaneity and give students time to ask questions. Maybe if one person has a question, someone else might have the same question. [In the current class] It seems like they want me to take time to answer someone's question, even if they haven't individually asked the question - there seems to be a group mindset in that way. (Interview 2:1/23)

This shows that Rebecca understands her learners' unique needs and desires in the context of her class. She has adapted to the students' cultural backgrounds and expectations in her current class in order to better meet their needs. The situated context in which a teacher functions is crucial to how effective he or she is as an educator. Woods (1996) also suggests that "expert teaching develops within the context of a teacher's background and within the context of a particular course and course goals" (p. 294). Rebecca's example shows that she not only thinks about the context of this particular course, but also about the specific cohort and these students' cultures and expectations.

The data indicates that Rebecca frequently sees opportunities to help students improve their understanding of English in the classroom. During an observation of one of Rebecca's classes, she chose to give the students their usual 10 
minute break after a group activity. This ended up being 10 minutes earlier than she had originally planned, but the students had begun talking amongst themselves after finishing the activity. She explained, "It seemed better to let them take their break rather than trying to refocus them for 10 minutes. Sometimes after a quiz, we'll take a break so they can have time to relax and refocus. I try to think about student energy like that" (Interview 2:1/23). Clearly, Rebecca made a pedagogical decision with the hope that it would improve the students' experience in the classroom and help them learn better. Likewise, Tsui (2003) describes Marina, an expert teacher, as "able to see the possibilities for ESL learning in her context of work, and by making use of these possibilities, she shaped a context that was conducive to ESL learning" (p. 254).

It is clear that Rebecca has an understanding of how to present subject matter to groups of students in appropriate ways. At the time of the videos as well as in her current classes, Rebecca teaches lower-level learners of English. During one of the stimulated recall sessions, she reflected on her previous teaching, "I noticed that I spoke clearly, slowly, and repeated a lot, which I think is appropriate for the group" (Interview 3:1/29). This shows that Rebecca has integrated an appropriate style of speech into her teaching for many years, from the time of the videos until now. She continued,

I definitely try to use language that is not confusing...just keep the language what you need to convey what you want them to do and don't say anything 
else. I'm conscious of keeping the language as simple as possible, breaking things down, repeating and keeping myself at a good volume. I noticed myself doing that there [in the video] too so that's good. It's heartening. (Interview $3: 1 / 29)$

This shows that Rebecca has learned which type of language is appropriate and helpful for lower-level students and she continues to use this style of language in her present teaching. 


\section{CHAPTER 5: CONCLUSION}

\section{SUMMARY OF FINDINGS}

There are three tentative conclusions that can be drawn from the results of this research. First, based on the characterizations of expertise described in this paper, Rebecca has developed into an expert teacher during the course of her teaching career because she demonstrates the characteristics of an expert outlined in prior research (Bereiter \& Scardamalia, 1993; Dreyfus \& Dreyfus, 1986; Farrell, 2013; Tsui, 2003, 2005). This study adopts the view that expertise is a process rather than a state to be achieved (Bereiter \& Scardamalia, 1993), and so there is not a clear indication that Rebecca 'became' an expert at a certain point in her career. However, based on the data available, at the time of the videos Rebecca did not appear to show all the discussed characteristics of an expert that she does in her current teaching. Therefore, it appears that from the time of the videos eight years ago to the current time, Rebecca shows more of the characteristics of an expert teacher.

Second, on the debate within the field of teacher expertise, this study has examined two different characterizations of expertise put forth by Dreyfus and Dreyfus (1986) and Bereiter and Scardamalia (1993). Tsui (2003), whose study corroborated Bereiter and Scardamalia (1993), sees expertise as requiring significant effort, even after many years of experience. Her expert teacher, Marina, still spent a significant amount of effort planning and modifying her lessons, making 
detailed notes of what she would ask students in class, and "problematizing the unproblematic," or working to improve certain facets of her teaching that she considered to be in need of improvement. These actions have been described by Bereiter and Scardamalia (1993) as "progressive problem solving", which is thought to be a crucial aspect of expertise (Bereiter and Scardamalia, 1993; Tsui, 2003). At the same time, Dreyfus and Dreyfus (1986) describe expertise as fluid, automatic, and instinctive. The "knowing how" and "knowing that" of teaching are integrated into an innate and spontaneous system in which teachers respond to classroom events based on their "hunches" or "intuitions" and often struggle to describe in detail exactly why they made certain judgments in a given situation.

From the data, we can see that Rebecca integrates aspects of both of these ideas. Tsui (2005) acknowledges that previous studies of outstanding teachers have shown that there appears to be some truth in both of these characterizations. Rebecca often described her knowledge of "knowing how," such as when she said, "I'm better at doing it than explaining it" (Interview 5:3/3). At the same time, Rebecca still plans detailed lessons and works to improve herself as a teacher. For example, she takes on enriching responsibilities at work, such as participating in TESOL conferences and working with a curriculum committee to redesign the curriculum for her class. These projects are not requirements for her job, but enrich her experience as a teacher. This indicates that "progressive problem solving" is an important aspect of Rebecca's teaching and has helped her overcome problems that have presented themselves throughout the course of her teaching. For Rebecca, 
aspects of both characterizations of expertise are important and present themselves in different ways in her teaching. This points to the possibility that in teaching, expertise can be characterized by both deliberate efforts to improve and a kind of intuitive decision making that informs classroom practices. Tsui (2005) suggests that the reason for this is a difference between "expertise" and "expert performance," such that "expert performance" is the fluid, automatic, and intuitive actions of an expert while "expertise" is the hard work and dedication to selfimprovement that helps an expert perform routinely and spontaneously. This thought-provoking characterization of the dual sides of expertise requires further studies so that we can fully understand the varying conceptions of teacher expertise.

Third, this study examined possible changes over an experienced teacher's career span based on the teacher's reflections about how her teaching has developed. The data shows that the most salient and important development in this teacher is her change in attitude. Watching her teaching from the time of the videos, Rebecca noticed many aspects of her teaching that had stayed relatively constant. For example, she noticed that she still speaks clearly and tries to include a lot of repetition to explain concepts clearly to students. However, she discussed an explicit positive change in her attitude that she experienced after the time of the videos that caused her to improve in various aspects of her teaching, such as moving away from feelings of teacher burnout and becoming excited about teaching again. What stood out the most was her more relaxed and authentic demeanor in the classroom and how much she enjoys the process of teaching now because she has 
greater mental energy for teaching. Furthermore, this shift in attitude has affected some of the small changes in her practice. Rebecca explained that when she watched her teaching in one of the videos, she felt that she would now speak more calmly and trust that she knows how to explain the content to students. This is because she feels more confident in the classroom and more excited about and energized by teaching. This seems to indicate that her change in attitude has had the greatest impact on her development into an expert teacher.

\section{LIMITATIONS}

This study is limited by the constraints of the data collection instruments used in this study. I could only describe the experience of my participant at the time of the video recordings in 2007 and during her teaching in 2015. It is therefore impossible to determine exactly how the participant's teaching evolved during the time in between. This study is also limited by the brevity of data collection. A more longitudinal study, in which more time could be devoted to examining both the teacher's current teaching and her previous teaching, would have likely led to more comprehensive and in-depth results about how the participant's cognition changed or did not change. Furthermore, Rebecca works in teacher education so she has spent time working with pre-service teachers on improving their teaching and this may have influenced some of her responses to my questions. Because not all teachers have teacher education experience, the process of developing expertise 
described in this study may not be reflective of teachers with different levels of experience in teacher education.

Because the design is a case study, the results are specific to one teacher in one context. As Kang and Cheng (2014) describe in their own study, a single case "cannot answer all the questions involved in so complicated a matter as teacher change" (p. 184). Teacher change and development appears to be a highly personal and contextually sensitive topic that can vary greatly amongst individuals. The influences and factors that helped my participant improve and develop into an expert teacher may not be relevant to teachers in other contexts. As in all qualitative research, there is an aspect of subjectivity inherent in the research process. The analysis was done through the lens of the researcher and is thus influenced by my biases as an individual. While this study does not provide the basis for any prescriptive conclusions, the purpose of this case study was never to generalize to teachers in other teaching programs. The rich, thick description that I obtained through careful description and analysis of one teacher could not have been accomplished with multiple participants.

The participant in this study is working within an intensive English program at an American university. Teachers in different contexts, such as community ESL or universities abroad, might have very different developmental trajectories and might show changes or consistencies that were different from those demonstrated by my participant. Tsui (2005) posits that there may be "cultural differences in perceptions 
about what constitutes expertise in teaching" (Tsui, 2005, p. 171). The teacher used in this study is operating within a pedagogical tradition specific to one culture. This teacher's experience in teacher education could be another factor, as teachers in different contexts may be more or less familiar with teacher education. Therefore, interpretations of what it means to be an expert teacher who demonstrates a commitment to students could be very different in other cultures (Tsui, 2005).

\section{IMPLICATIONS AND SUGGESTIONS FOR FURTHER RESEARCH}

These limitations highlight several areas for further research. In case study research, many case studies on one topic can be generalized to make stronger conclusions about that topic. The present study was designed to contribute to the larger body of research on teacher expertise and further case studies, over longer periods of time, would lead to a greater understanding of the development of expertise over time. Tsui (2003) also suggests that experienced teachers can look to case studies of their peers for greater understanding and awareness of their own teaching. An expert teacher's ways of learning and teaching "may serve as a reference for both novice and experienced teachers to think about their work as teachers" (p. 281). Understanding expert teachers' mechanism of developing expertise can also contribute to teacher education by serving as guides to preservice teachers and giving them the tools to know how to improve. Thus, the present case study can contribute to both the larger field and individual teachers seeking to better understand their own teaching and how to improve. 
Rebecca reported several areas in which her teaching appears to have changed and several that have remained relatively constant. This might mean that as teachers develop over time, they do not necessarily need to demonstrate changes in many or most areas of their teaching. If an aspect of their teaching is working, it is not necessary to change it in order to become a more effective teacher. A teacher who understands what is effective in the classroom will likely be better able to determine what in her teaching needs to be improved and what needs to remain consistent. Thus, for this teacher some changes and some consistencies were necessary for her to develop the characteristics of an expert teacher. Further research is needed to better understand to what degree change is necessary for development of expertise.

Expertise in teaching is a highly complex area of teacher cognition that can be best understood through further research into how teachers develop expertise over time. There continues to be a debate over whether expertise should be characterized as tacit and automatic or deliberate and effortful (Tsui, 2005). Further research into how to best characterize expertise in teaching is needed before we have a strong understanding of this construct as a whole and how to encourage teachers to develop into expert teachers. By better understanding how teachers develop expertise, we can begin to recognize the stages they go through on their way to becoming and maintaining expertise. Being able to identify the factors that help a teacher develop into an expert can help teacher educators to identify and encourage those factors in pre-service and less experienced teachers. Tsui (2005) 
writes that understanding the processes and learning mechanisms that "mediate and support the development of expertise" is very valuable to fully comprehending the nature of expertise (p. 184).

Clearly there are different ways of viewing the mental representations of teaching that we see in experts. Therefore, further research into understanding how expertise is developed and maintained is necessary. As Bell (2005) states, "Foreign language teaching is a complex, multi-dimensional process that means different things to different people" (pp. 259-260). But despite its complexity, it is still valuable to work to develop a greater understanding of how to mold and create effective teachers. Thus, further research should continue to explore how teachers learn the skills and knowledge to develop into experts and how to best incorporate these processes into improving teachers' capacity to develop expertise. 


\section{REFERENCES}

Alger, C. (2009). Secondary teachers' conceptual metaphors of teaching and learning: changes over the career span. Teaching and Teacher Education: An International Journal of Research and Studies, 25(5), 743-751.

Basturkmen, H. (2012). Review of research into the correspondence between language teachers' stated beliefs and practices, System, 40 (2), 282-295.

Basturkmen, H., Loewen, S., Ellis, R. (2004). Teachers' stated beliefs about incidental focus on form and their classroom practices. Applied Linguistics, 25(2), 243272.

Bell, T. (2005). Behaviors and attitudes of effective foreign language teachers: Results of a questionnaire study. Foreign Language Annals, 38, 259-270.

Bereiter, C. \& Scardamalia, M. (1993). Surpassing ourselves: An inquiry into the nature and implications of expertise. Chicago, IL: Open Court Publishing.

Borg, S. (2003). Teacher cognition in language teaching: A review of research on what language teachers think, know, believe, and do. Language Teaching, 36(2), 81-109.

Borg, S. (2011). The impact of in-service education on language teachers' beliefs. System, 39(3), 370-380 
Breen, M., Hird, B., Milton, M., Oliver, R., \& Thwaite, A. (2001). Making sense of language teaching: teachers' principles and classroom practices. Applied Linguistics, 22(4), 470-501.

Burns , A. (1992). Teacher beliefs and their influence on classroom practice. Prospect, 7(3), 56-66.

Carter, K., \& Doyle, W. (1995). Preconceptions in learning to teach. The Educational Forum, 59(2), 186-195.

Crookes, G. \& Arakaki, L. (1999). Teaching idea sources and work conditions in an ESL program. TESOL Journal, 8(1), 15-19.

Dreyfus, H.L. \& Dreyfus, S.E. (1986). Mind over machine. New York, NY: Free Press.

Ellis, E. (2006). Language learning experience as a contributor to ESOL teacher cognition. TESL-EJ, 10(1), Retrieved from: http://tesl-ej.org/ej37/a3.html.

Fang, Z. (1996). A review of research on teacher beliefs and practices. Educational Research, 38(1), 47-65.

Farrell, T. \& Bennis, K. (2013). Reflecting on ESL teacher beliefs and classroom practices: A case study. RELC Journal, 44(2), 163-176.

Flowerdew, J. (1998). Language learning experience in L2 teacher education. TESOL Quarterly, 32(3), 529-535. 
Freeman, D. (1989). Teacher training, development, and decision making: A model of teaching and related strategies for language teacher education. TESOL Quarterly, 23(1), 27-45.

Freeman, D. \& Richards, J. (1993). Conceptions of teaching and the education of second language teachers. TESOL Quarterly, 27(2), 193-216.

Fuller, F. (1969). Concerns of teachers: A developmental conceptualization. American Educational Research Journal, 6(2), 207-226.

Hoy, A. \& Spero, R. (2005). Changes in teacher efficacy during the early years of teaching: A comparison of four measures. Teaching and Teacher Education, $21,343-356$.

Kang, Y \& Cheng, X. (2014). Teacher learning in the workplace: A study of the relationship between a novice EFL teacher's classroom practices and cognition development. Language Teaching Research, 18(2), 169-186.

Kuzborska, I. (2011). Links between teachers' beliefs and practices and research on reading. Reading in a Foreign Language, 23(1), 102-128.

Leinardt, G. \& Greeno, J. (1986). The cognitive skill of teaching. Journal of Educational Psychology, 78(2), 75-95.

Lortie, D. (1975). Schoolteacher: A sociological study. Chicago, IL: University of Chicago Press. 
Macalister, J. (2012). Pre-service teacher cognition and vocabulary teaching. RELC Journal, 43(1), 99-111.

Mackey, A. \& Gass, S. (2000). Stimulated recall methodology in second language research. Mahwah, NJ: Lawrence Erlbaum Associates, Inc.

Mackey, A. \& Gass, S. (2005). Second language research: Methodology and design. Mahwah, NJ: Lawrence Erlbaum Associates, Inc.

Mann, S. (2005). The language teacher's development. Language Teaching, 38, 103118.

Mok, W. (1994). Reflecting on reflections: A case study of experienced and inexperienced ESL teachers. System, 22(1), 93-111.

Nespor, J. (1987). The role of beliefs in the practice of teaching. Journal of Curriculum Studies, 19(4), 317-328.

Nunan, D. (1992). The teacher as decision-maker. In J. Flowerdew, M. Brock \& S. Hsia (Eds.), Perspectives on second language teacher education (pp. 135-165). Hong Kong: City Polytechnic.

Pickering, A. (2005). Harnessing influences for change: Some implications from research for teacher educators. In L. Clandfield (Ed.), Affect and self-esteem in teacher education (pp. 17-26). Kent: Whitstable. 
Pigge, F. \& Marso, R. (1997). A seven year longitudinal multi-factor assessment of teaching concerns development through preparation and early years of teaching. Teaching and Teacher Education, 13, 225-235.

Ping, W. (2010). Managing change in English language teaching through a journey of learning: A case study from China. European Journal of Teacher Education, $33(4), 437-445$.

Portland State University. (2014). About IELP. Retrieved from http://www.pdx.edu/esl/about-ielp

Reder, S., Harris, K. A., \& Setzler, K. (2003). A multimedia adult learner corpus. TESOL Quarterly, 37, 546-557.

Reder, S. (2005). The “Lab School.” Focus on Basics, 8a, 1-6.

Reeves, J. (2009). A sociocultural perspective on ESOL teachers' linguistic knowledge for teaching. Linguistics and Education, 20, 109-125.

Richards, J. C. (1996). Teachers' maxims in language teaching. TESOL Quarterly, 30(2), 281-296.

Richards, J. C. (2010). Competence and performance in language teaching. RELC Journal, 41(2), 101-122. 
Richards, J., Li, B., \& Tang, A. (1998). Exploring pedagogical reasoning skills. In J. C. Richards (Ed.), Beyond Training (pp. 86-102). Cambridge: Cambridge University Press.

Ryle, G. (1949). The concept of mind. Chicago, IL: University of Chicago Press.

Sanchez, H. (2013). A cognitive perspective on pre-service and in-service language teaching. Babylonia, 21(1), 51-56.

Sendan, F. \& Roberts, J. (1998). Orhan: A case study in the development of a student teacher's personal theories. Teachers and Teaching: Theory and Practice, 4(2), 229-244.

Sun, D. (2012). "Everything goes smoothly": A case study of an immigrant Chinese language teacher's personal practical knowledge. Teaching and Teacher Education, 28(5), 760-767.

Tsui, A. (2003). Understanding expertise in teaching: Case studies of second language teachers. Cambridge: Cambridge University Press.

Tsui, A. (2005). Expertise in teaching: Perspectives and issues. In K. Johnson (Ed.), Expertise in second language learning and teaching (pp. 167-189). New York, NY: Palgrave Macmillan. 
Verloop, N., Van Driel, J., \& Meijer, P. (2001). Teacher knowledge and the knowledgebase of teaching. International Journal of Educational Research, 35, $441-61$.

Wong, R. (2013). The sustainability of change in teacher beliefs and practices as a result of an overseas professional development course. Journal of Education for Teaching, 39(2), 152-168.

Woods, D. (1996). Teacher cognition in language teaching: Beliefs, decision-making and classroom practice. Cambridge: Cambridge University Press.

Woods, D. \& Cakir, H. (2011). Two dimensions of teacher knowledge: The case of communicative language teaching. System, 39, 290-381.

$\mathrm{Xu}, \mathrm{H}$. (2013). From the imagined to the practiced: A case study on novice EFL teachers' professional identity change in China. Teaching and Teacher Education, 31, 79-86.

Yazdi, M., Motallebzadeh, K., \& Ashraf, H. (2014). The role of teacher's self-efficacy as a predictor of Iranian EFL teacher's burnout. Journal of Language Teaching \& Research, 5(5), 1198-1204.

Zheng, H. (2013). Teachers' beliefs and practices: A dynamic and complex relationship. Asia-Pacific Journal of Teacher Education, 41(3), 331-343. 


\section{APPENDIX}

Sample Interview Questions: Stimulated recall

1. How did you feel about the class?

2. When you watch the video, do you notice ways that your teaching has changed or not changed?

3. To what do you attribute these changes or lack of changes?

\section{$\underline{\text { Sample Interview Questions: Post-observations }}$}

1. Can you think of any ways that your teaching beliefs have changed over the years or have they remained constant? What do you think accounts for this change or lack of change?

2. Are you concerned about the impact your class will have on your students?

3. We've discussed teaching context some already in terms of the academic vs. the community contexts, so I want to know a little more about this subject. How does your teaching context inform your teaching decisions?

4. Do you use or draw on a repertoire of teaching strategies and activities in the classroom? 